SFB 649 Discussion Paper 2016-059

\title{
Dynamic credit default swaps curves in a network topology
}

\author{
Xiu $\mathrm{Xu} *$ \\ Cathy Yi-Hsuan Chen * \\ Wolfgang Karl Härdle *
}

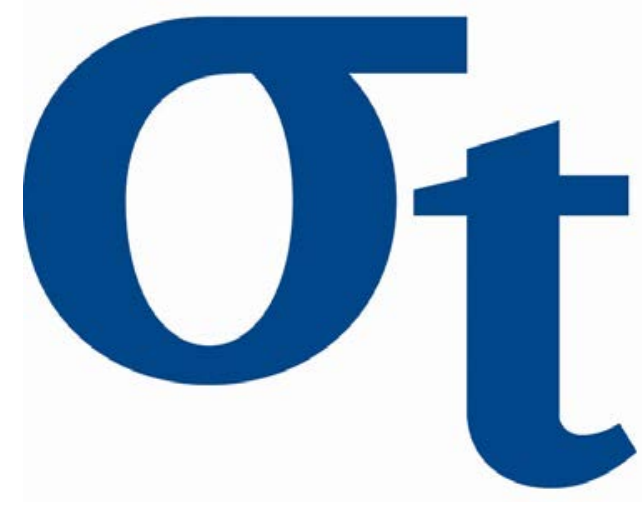

* Humboldt-Universität zu Berlin, Germany

の

寸

6

صำ

This research was supported by the Deutsche Forschungsgemeinschaft through the SFB 649 "Economic Risk".

http://sfb649. wiwi. hu-berlin.de ISSN 1860-5664 


\title{
Dynamic credit default swaps curves in a network
} topology ${ }^{*}$

\author{
Xiu Xu $\mathrm{Xu}^{\dagger}$ Cathy Yi-Hsuan Chen ${ }^{\ddagger}$ Wolfgang Karl Härdle ${ }^{\S}$
}

\begin{abstract}
Systemically important banks are connected and have dynamic dependencies of their default probabilities. An extraction of default factors from cross-sectional credit default swaps (CDS) curves allows to analyze the shape and the dynamics of the default probabilities. Extending the Dynamic Nelson Siegel (DNS) model, we propose a network DNS model to analyze the interconnectedness of default factors in a dynamic fashion, and forecast the CDS curves. The extracted level factors representing long-term default risk demonstrate $85.5 \%$ total connectedness, while the slope and the curvature factors document $79.72 \%$ and $62.94 \%$ total connectedness for the short-term and middle-term default risk, respectively. The issues of default spillover and systemic risk should be weighted for the market participants with longer credit exposures, and for regulators with a mission to stabilize financial markets. The US banks contribute more to the long-run default spillover before 2012, whereas the European banks are major default transmitters during and after the European debt crisis either in the long-run or short-run. The outperformance of the network DNS model indicates that the prediction on CDS curve requires network information.
\end{abstract}

JEL classification: C32, C51, G17

Keywords: CDS, network, default risk, variance decomposition, risk management

*Financial support from the Deutsche Forschungsgemeinschaft via CRC 649 "Economic Risk" and IRTG 1792 "High Dimensional Non Stationary Time Series", Humboldt-Universität zu Berlin, is gratefully acknowledged.

${ }^{\dagger}$ Humboldt-Universität zu Berlin, C.A.S.E. - Center for Applied Statistics and Economics, Spandauer Str.1, 10178 Berlin, Germany, tel: +49 (0)30 2093 5807, email: xiu.xu@hu-berlin.de

${ }^{\ddagger}$ Humboldt-Universität zu Berlin, C.A.S.E. - Center for Applied Statistics and Economics, Spandauer Str.1, 10178 Berlin, Germany, tel: +49 (0)30 2093 5625, email: cathy.chen@hu-berlin.de

${ }^{\S}$ Humboldt-Universität zu Berlin, C.A.S.E. - Center for Applied Statistics and Economics, Spandauer Str. 1, 10178 Berlin, Germany and Sim Kee Boon Institute for Financial Economics, Singapore Management University, 81 Victoria Street, Singapore 188065, email: haerdle@hu-berlin.de 


\section{Introduction}

Probability of default (PD) is the likelihood of a default with respect to obligations over a particular time horizon. A PD 'curve' used to map PDs with horizons typically shows an upward slope, although occasionally it may display a downward slope to signal a severe credit deterioration in the short-run relative to long-run. The PD curve varies in time and as in the analysis of term structure for CDS spreads, carries information on comovements and common factors. An extraction of common factors from cross-sectional credit default swaps (CDS) spreads allows to analyze the shape and the dynamics of the PD. To be more specific, the shape of PD curve can be parsimoniously inferred by projecting the cross-sectional CDS spreads with different maturities to a few numbers of factors. The dynamics of curves and their interplay which is casted into network topology reflecting the interdependency in a controllable dimensionality.

This study strives to analyze the term structure of CDS spreads (or CDS curves) in several aspects (1) extract the short-Term(ST), middle-Term(MT) and long-Term(LT) default factor from CDS curves; (2) quantify their comovements and identify the firms being downgraded simultaneously; (3) model the default spillover in the ST, MT and LT perspective, respectively; (4) predict the CDS curves based on the calibrated dynamics.

The initial question tagging on the above attempts is why one needs to look at the CDS spreads and its information content. Han and Zhou (2015) pointed out the various advantages of CDS over bond spreads: CDS spreads are not subject to the specification of benchmark risk-free yield curve (Longstaff et al., 2005), less contaminated by nondefault risk components (Ericsson et al. 2009) and have better price discovery in credit condition (Blanco et al., 2005). Most notably, the default intensity and recovery rate of a bond can be derived, based on a number of CDS spreads pricing models, from the market prices of CDS spreads. The CDS curve yields information on the risk-neutral default probability over different time horizons. Market participants rely on this curve to interpret the market 'expectation' of default risk in different time frames (ST, MT, LT), to manage credit risk and to design credit derivative contracts. Moreover, analogous with interest rate expectations hypothesis, the difference between current LT and ST CDS spreads can be used to predict future changes in ST CDS spreads. 
The proposal made here is to employ a factor model with shapes as in the Dynamic Nelson-Siegel (DNS). The derived latent factors are time series with the dynamics portrayed, and can be estimated by a two-stages least square procedure or by a state space approach. The economic underpinning of the DNS model is that the three latent factors distilled from cross-sectional CDS spreads over maturities ideally represent the ST, the MT and the LT factor in terms of default. Having these extracted common factors, one can dive directly into the credit horizons of interest.

Nowadays the fear of default risk is transferring from an individual case into a systemic impact which is more likely to break down the architecture of financial interdependence. For example, a default event of a bank can be regarded as systemic if its failure or extreme turbulence results in a directly widespread distress or indirectly triggers a contagion. This issue is of importance for financial industry due to their correlated exposure holdings or direct interbank obligations, this is the very reason in this research we focus our sample on the global systemically important banks (G-SIBs). To stabilize financial markets, Financial Stability Board (FSB) strives to identify the systemic important ones and rank the financial institutions in terms of their systemic relevance. To address this issue, we develop and apply a unified framework, namely "the network topology of variance decompositions", for quantifying default spillover, contagion or interconnectedness. Given the ST, MT and LT credit factor extracted from the DNS model, it is of interest to what extent the credit condition of bank $i$ is subject to its past credit but also the credit conditions of other banks due to interbank relationship. Will credit spillover or contagion evenly be observed in the ST or LT credit horizon or both? Can we use this information to foresee crisis and evaluate the tension embedded in the credit assets with different maturities?

It's worthwhile to relate the aforementioned issues to CDS pricing and forecast. Pricing CDS contracts is suggested to take credit spillover into account, especially for the reference entities whose default intensity is vulnerable to others. Likewise, one may produce better out-of-sample forecast performance in CDS curve with this consideration. Note that the forecast here is for an entire curve instead of a point prediction. The forecast is valuable for the counterparties in the both sides of CDS contract. For buyers, the forecast is very decisive for the timing of gauging a CDS contract to hedge credit risk at the earlier stage 
of default likelihood. They can benefit through a relatively lower insurance payment. For sellers, with default network information, they avoid underestimating CDS spreads. We will demonstrate the forecast implementation in the later section. This study also contributes to the bondholders with different time horizons of credit exposures; to policy makers with policy goals setting for the ST and the LT perspective; to the portfolio managers for diversifying their bond portfolios; and to credit agencies for rating firms' credits in different time frames.

Our primary findings are:(1) G-SIBs banks have comoving credit curves with high connectedness, especially in the long-term. The US banks contribute more to the long-term default spillover before 2012, whereas the European banks are major default transmitters during and after the European debt crisis either in the long-term or short-term. (2) the time-varying total default connectedness serves as an indicator for systemic risk, especially for identifying a clustering default subsystem. The TED spread, credit spread and VIX are main determinants of default connectedness. (3) The network-based DNS model, relative to the DNS model, yields better out-of-sample prediction for CDS curves.

The remainder of the paper is organized as follows: the network-based DNS model is introduced in Section 2, model estimation is detailed in Section 3 . Section 4 describes the data and offers preliminary analysis. We summarize the empirical results and detail the analysis of static and dynamic connectedness measures in Section 5. Finally, Section 6. concludes.

\section{Modeling framework}

The beginning of this section details the procedures of modeling the CDS curves with Dynamic Nelson Siegel (DNS) framework, in which the three Nelson Siegel parameters, i.e., level, slope and curvature, can be viewed as the long, medium and short term factor of the CDS curves. Further, to tackle systemic default, credit contagion or spillover, and network connectedness of default, we utilize the Diebold-Yilmaz connectedness measures, which rely on the variance decompositions in a vector autoregressive (VAR) model. In addition, the out-of-sample forecasting framework with or without other bank's information 
are also introduced.

\subsection{Fitting the CDS curve via the Dynamic Nelson Siegel model}

\subsubsection{A factor model representation}

Nelson and Siegel (1987) propose a PCA based parsimonious three factor model for modelling the cross-sectional yields at any point. Diebold and Li (2006) extend this into the DNS framework and find excellent forecasting properties for interest rates. Diebold et al. (2006) model the yield curve via a state space factorization and find strong influences from macro variables.

Likewise, the CDS curves have a similar term structure framework so that a natural progression is an application of the CDS curves (Shaw et al., 2014, Krishnan et al., 2010). Define $y_{i t}(\tau)$ as the nominal CDS spreads of financial institution $i$ on a vector comprised of $\tau-$ period maturities. $\tau=\left(\tau_{1}, \tau_{2}, \cdots, \tau_{k}\right)=(6 M, 1 Y, 2 Y, 3 Y, 4 Y, 5 Y, 7 Y, 10 Y, 20 Y, 30 Y)$, $k=10$. The DNS factorization for a single financial institute $i$ at time point $t$ is,

$$
\begin{aligned}
& y_{i t}(\tau)=l_{i t}+s_{i t}\left\{\frac{1-\exp \left(-\delta_{i} \tau\right)}{\delta_{i} \tau}\right\}+c_{i t}\left\{\frac{1-\exp \left(-\delta_{i} \tau\right)}{\delta_{i} \tau}-\exp \left(-\delta_{i} \tau\right)\right\}+v_{i t}(\tau) \\
& \left(\begin{array}{c}
l_{i t} \\
s_{i t} \\
c_{i t}
\end{array}\right)=\left(\begin{array}{ccc}
\alpha_{i}^{l} & 0 & 0 \\
0 & \alpha_{i}^{s} & 0 \\
0 & 0 & \alpha_{i}^{c}
\end{array}\right)\left(\begin{array}{c}
l_{i, t-1} \\
s_{i, t-1} \\
c_{i, t-1}
\end{array}\right)+\left(\begin{array}{c}
\varepsilon_{i t}^{l} \\
\varepsilon_{i t}^{s} \\
\varepsilon_{i t}^{c}
\end{array}\right) \\
& \left(\begin{array}{c}
v_{i t} \\
\varepsilon_{i t}
\end{array}\right) \sim \text { i.i.d.N }\left[\left(\begin{array}{c}
0 \\
0
\end{array}\right),\left(\begin{array}{cc}
Q_{i} & 0 \\
0 & \Sigma_{i}
\end{array}\right)\right]
\end{aligned}
$$

where the disturbance vector $v_{i t}=\left[v_{i t}\left(\tau_{1}\right), v_{i t}\left(\tau_{2}\right), \cdots, v_{i t}\left(\tau_{k}\right)\right]^{\top}$ and $\varepsilon_{i t}=\left(\varepsilon_{i t}^{l}, \varepsilon_{i t}^{s}, \varepsilon_{i, t}^{c}\right)^{\top}$. The parameter matrix $\alpha_{i}$ is diagonal in transition equation. $\delta$ the constant decay factor (here $\delta=0.0609$ ). We varied the decay factors and estimated it for each bank, however it changes little on the results, therefore, for simplicity it is set to be a constant. $y_{i t}(\tau)$ is the so-called term structure of CDS spreads or CDS curve of institution $i$ at time $t$.

The three DNS parameters $l_{i t}, s_{i t}$, and $c_{i t}$ can be interpreted as LT, ST, and MT latent factors. Since the factor loading on $l_{i t}$ is 1 , which is a constant and the same for all 
maturities, $l_{i t}$ can be viewed as the long-term or level factor. Any increase in $l_{i t}$ will cause the entire curve to shift upwards, representing the 'level' and 'long-run' components of credit curve. The factor loading of $s_{i t}$ is $\frac{1-\exp \left(-\delta_{i} \tau\right)}{\delta_{i} \tau}$, starting from 1 and exponentially deceasing to 0, can be viewed as the ST factor. The 'slope' of credit curve is changing accordingly. The loading of $c_{i t}$ is $\frac{1-\exp \left(-\delta_{i} \tau\right)}{\delta_{i} \tau}-\exp \left(-\delta_{i} \tau\right)$, a function which starts from 0 then increases and decays to 0 , hence it is the MT factor. In sum, the shape of the credit curve is captured by these three factors. A time-varying shape is reflected by the changing loads on the three factors.

For the purpose of depicting the interplay of projected factors among banks, one has the challenge to calibrate the dynamics of $l_{i t}, s_{i t}$, and $c_{i t}$ as e.g. a VAR(1) process. This motivates us to study dynamically evolving $l_{i t}, s_{i t}$, and $c_{i t}$. Ideally, the DNS model for each bank immediately forms a state-space system as expressed in (2). Motivated by PCA, we assume the level factor, the slope, and the curvature factor are orthogonal. The parameter matrix $\alpha_{i}$ is diagonal in transition equation. For this state space system, we will resort to the Kalman filter estimation method. We, therefore, assume the disturbance vector $v_{i t}$ and $\varepsilon_{i t}$ to be independent and both follow a normal distribution with covariance matrix $Q_{i}$ and $\Sigma_{i}$ respectively. By doing so, one can distill the entire CDS curves, period by period, into three dynamically evolving dimensional parameters and model their interplay characterized by a $\operatorname{VAR}(1)$ process.

\subsection{Network topology of DNS factors}

Joint default may become systemic in the moment as banks call for bailout together or even go bankrupt sequentially. The fact of correlated default and default spillover draws more attention (see Duffie et al. (2009); Duan and Miao (2015)). Due to interbank loans and shared credit exposures, a default risk of one bank can easily spread to others. The speed and scope of spread is subject to bank's systemic importance. We introduce a network topology of variance decomposition to measure the 'credit connectedness' which quantifies the scope of 'default risk transmission'. The embedded dynamics mechanism allows us to evaluate the speed of default risk transmission. 


\subsubsection{Approximating model - VAR}

We endow the level, the slope, and the curvature factors with a $\operatorname{VAR}(p)$ dynamics:

$$
\begin{aligned}
& x_{t}=\sum_{k=1}^{p} A_{k} x_{t-k}+u_{t}, u_{t} \sim i . i . d . \mathrm{N}(0, \Sigma) \\
& x_{t}=\left(x_{1 t}, x_{2 t}, \cdots, x_{N t}\right)^{\top}
\end{aligned}
$$

where $x_{t}$ represents $l_{t}=\left(l_{1 t}, l_{2 t}, \cdots, l_{N t}\right)^{\top}, s_{t}=\left(s_{1 t}, s_{2 t}, \cdots, s_{N t}\right)^{\top}, c_{t}=\left(c_{1 t}, c_{2 t}, \cdots, c_{N t}\right)^{\top}$. $N$ is the number of banks, in our case, $N=10$. The autoregression matrix $A_{k}$ is $N \times N$ dimensional, $p$ denotes the lag order of VAR. If the lag order is identically equal to 1 for $l_{i t}, s_{i t}$, and $c_{i t}$, then equation (3) represents,

$$
\begin{aligned}
& l_{t}=\left(\begin{array}{c}
l_{1 t} \\
l_{2 t} \\
\vdots \\
l_{N t}
\end{array}\right)=\left(\begin{array}{cccc}
\alpha_{11}^{l} & \alpha_{12}^{l} & \cdots & \alpha_{1 N}^{l} \\
\alpha_{21}^{l} & \alpha_{22}^{l} & \cdots & \alpha_{2 N}^{l} \\
\vdots & \vdots & \cdots & \vdots \\
\alpha_{N 1}^{l} & \alpha_{N 2}^{l} & \cdots & \alpha_{N N}^{l}
\end{array}\right)\left(\begin{array}{c}
l_{1, t-1} \\
l_{2, t-1} \\
\vdots \\
l_{N, t-1}
\end{array}\right)+\left(\begin{array}{c}
u_{1 t}^{l} \\
u_{2 t}^{l} \\
\vdots \\
u_{N t}^{l}
\end{array}\right) \\
& s_{t}=\left(\begin{array}{c}
s_{1 t} \\
s_{2 t} \\
\vdots \\
s_{N t}
\end{array}\right)=\left(\begin{array}{cccc}
\alpha_{11}^{s} & \alpha_{12}^{s} & \cdots & \alpha_{1 N}^{s} \\
\alpha_{21}^{s} & \alpha_{22}^{s} & \cdots & \alpha_{2 N}^{s} \\
\vdots & \vdots & \cdots & \vdots \\
\alpha_{N 1}^{s} & \alpha_{N 2}^{s} & \cdots & \alpha_{N N}^{s}
\end{array}\right)\left(\begin{array}{c}
s_{1, t-1} \\
s_{2, t-1} \\
\vdots \\
s_{N, t-1}
\end{array}\right)+\left(\begin{array}{c}
u_{1 t}^{s} \\
u_{2 t}^{s} \\
\vdots \\
u_{N t}^{s}
\end{array}\right) \\
& c_{t}=\left(\begin{array}{c}
c_{1 t} \\
c_{2 t} \\
\vdots \\
c_{N t}
\end{array}\right)=\left(\begin{array}{cccc}
\alpha_{11}^{c} & \alpha_{12}^{c} & \cdots & \alpha_{1 N}^{c} \\
\alpha_{21}^{c} & \alpha_{22}^{c} & \cdots & \alpha_{2 N}^{c} \\
\vdots & \vdots & \cdots & \vdots \\
\alpha_{N 1}^{c} & \alpha_{N 2}^{c} & \cdots & \alpha_{N N}^{c}
\end{array}\right)\left(\begin{array}{c}
c_{1, t-1} \\
c_{2, t-1} \\
\vdots \\
c_{N, t-1}
\end{array}\right)+\left(\begin{array}{c}
u_{1 t}^{c} \\
u_{2 t}^{c} \\
\vdots \\
u_{N t}^{c}
\end{array}\right)
\end{aligned}
$$

It is well known that the VAR model (3) (if stationary) can be written as $x_{t}=\Theta(L) u_{t}$, $\Theta(L)=\Theta_{0}+\Theta_{1} L+\ldots \Theta_{h} L^{h}+\ldots, \Theta_{i}=A_{1} \Theta_{i-1}+A_{2} \Theta_{i-2}+\cdots+A_{p} \Theta_{i-p}$, where $\Theta_{0}$ and $A_{0}$ are $N \times N$ identity matrix, $A_{i}=0$ for $i<0$. This representation allows us to extract connectedness information. Following Diebold and Yilmaz (2014), we resort to apply this variance decomposition to establish a network structure. 


\subsubsection{Pairwise directional default connectedness}

Default connectedness measures the shares of forecast error variation due to shocks arising from others. This is captured by the variance decomposition, in which the forecast error variance of variable $i$ is decomposed into parts attributed to the remaining variables in the system. The generalized variance decomposition (GVD) (Koop et al., 1996) yields $\tilde{d}_{i j}(H)$ as the $i j$-th $H$-step component, which represents the fraction of bank $i$ 's $H$-step forecast error variance due to credit shocks in bank $j$,

$$
\tilde{d}_{i j}(H)=\frac{\sigma_{j j}^{-1} \sum_{h=0}^{H-1}\left(e_{j}^{\top} \Theta_{h} \Sigma e_{j}\right)^{2}}{\sum_{h=0}^{H-1}\left(e_{i}^{\top} \Theta_{h} \Sigma \Theta_{h}^{\top} e_{i}\right)}
$$

where $\sigma_{j j}$ is the $j$ th diagonal element in the covariance matrix $\Sigma$ of the error vector $u_{t}$, that is, the standard deviation of the error term of $j$ th equation, and $e_{j}=(0,0, \ldots, 1, \ldots, 0)$, a zero vector except $j$ th element unity. $H$ denotes the forecast horizon.

Since the sum of $\tilde{d}_{i j}(H)$ in each equation does not necessarily equal to unit, that is, $\sum_{j=1}^{N} \tilde{d}_{i j}(H) \neq 1$, we normalize as follows:

$$
d_{i j}(H)=\frac{\tilde{d}_{i j}(H)}{\sum_{j=1}^{N} \tilde{d}_{i j}(H)}
$$

Define the pairwise directional credit connectedness from bank $j$ to bank $i$ as $C_{i \leftarrow j}=$ $d_{i j}(H)$, and note that in general $C_{i \leftarrow j} \neq C_{j \leftarrow i}$. This leads finally to the connectedness in Table 1 .

Table 1: Connectedness table

\begin{tabular}{llllll}
\hline \hline & $x_{1}$ & $x_{2}$ & $\cdots$ & $x_{N}$ & From others \\
\hline$x_{1}$ & $d_{11}$ & $d_{12}$ & $\cdots$ & $d_{1 N}$ & $\sum_{j=1}^{N} d_{1 j}, j \neq 1$ \\
$x_{2}$ & $d_{21}$ & $d_{22}$ & $\cdots$ & $d_{2 N}$ & $\sum_{j=1}^{N} d_{2 j}, j \neq 2$ \\
$\vdots$ & $\vdots$ & $\vdots$ & $\ddots$ & $\vdots$ & $\vdots$ \\
$x_{N}$ & $d_{N 1}$ & $d_{N 2}$ & $\cdots$ & $d_{N N}$ & $\sum_{j=1}^{N} d_{N j}, j \neq N$ \\
\hline To others & $\sum_{i=1}^{N} d_{i 1}$ & $\sum_{i=1}^{N} d_{i 2}$ & $\cdots$ & $\sum_{i=1}^{N} d_{i N}$ & $\frac{1}{N} \sum_{i, j=1}^{N} d_{i j}$ \\
& $i \neq 1$ & $i \neq 2$ & & $i \neq N$ & $i \neq j$ \\
\hline \hline
\end{tabular}

Note that a higher $H$ horizon in a higher prediction error variance, a higher value of $C_{i \leftarrow j}$. When $H$ is very small, it limits $C_{i \leftarrow j}$ to short periods. On the other hand, as $H$ 
increases the corresponding $C_{i \leftarrow j}$ increases slightly due to the incrementally less valuable conditioning information. For the case $H \rightarrow \infty$, one obtains an unconditional variance decomposition. To strike a balance between these effects, we select $H=12$. It is close to the time period (10 days) of value at risk (VaR) required under the Basel accord, and also in the practical rebalancing interval of portfolio management. In the empirical part, we also calculate the results for a range of horizons, it turns out that when $H$ is larger than a certain value, around $10, C_{i \leftarrow j}$ increases trivially. We can provide a robustness check for other $H$ if required.

\subsubsection{Interpreting the connectedness}

Consider as an example of the first row of Table 1 , the sum of the off-diagonal $d_{i j}, j \neq i$ of bank 1 accounts for shocks attributed to other banks, while as for the first column, the sum of $d_{i 1}, j \neq 1$ indicates the risk contribution of bank 1 . Total directional connectedness from others to $i$ is

$$
C_{i \leftarrow \bullet}=\sum_{j=1, j \neq i}^{N} d_{i j}(H)
$$

Likewise, the total directional connectedness to others from $j$ is

$$
C_{\bullet \leftarrow j}=\sum_{i=1, i \neq j}^{N} d_{i j}(H)
$$

The net default connectedness $i$ is the difference 'To' and 'From':

$$
C_{i}=C_{\bullet \leftarrow i}-C_{i \leftarrow \bullet}
$$

The total default connectedness is:

$$
C=\frac{1}{N} \sum_{i, j=1, j \neq i}^{N} d_{i j}(H)
$$

Note that there are $N$ 'To' and 'From' net connectedness adding up to total connectedness. Economically speaking, as $C$ increases, banks spread default risk mutually. Hence, $C$ in 13 is a quantitative measure of default spillover or contagion in a system. 


\subsection{Out-of-sample forecasts}

To evaluate the informativeness of the predefined network connectedness, it is of interest to compare the forecasting performance between the network-based DNS model and the conventional DNS model. Using (3) one predicts:

$\widehat{y}_{i, t+h \mid t}(\tau)=\widehat{\beta}_{i 1, t+h \mid t}+\widehat{\beta}_{i 2, t+h \mid t}\left\{\frac{1-\exp (-\delta \tau)}{\delta \tau}\right\}+\widehat{\beta}_{i 3, t+h \mid t}\left\{\frac{1-\exp (-\delta \tau)}{\delta \tau}-\exp (-\delta \tau)\right\}$

where $\widehat{\beta}_{i s, t}, s=1,2,3$ denotes $\widehat{l}_{i t}, \widehat{s}_{i t}, \widehat{c}_{i t}$ respectively, and can be estimated through (1) and $(2)$.

The autoregressive process of transition equation without the influence from the latent factors of other banks, named as DNS-AR(1),

$$
\widehat{\beta}_{i s, t+h \mid t}=\widehat{\gamma}_{i s}^{0}+\widehat{\gamma}_{i s} \widehat{\beta}_{i s, t}
$$

As the forecast model comparison, the transition equation in a multivariate factor framework to undertake their interaction, named as DNS-VAR(1),

$$
\widehat{\beta}_{i s, t+h \mid t}=\widehat{\gamma}_{i s}^{0}+\widehat{\gamma}_{i s} \widehat{\beta}_{i s, t}+\widehat{\phi}_{j s} \widehat{\beta}_{j s, t}, j \neq i
$$

where $\widehat{\beta}_{j s, t}$ is the latent factors from other banks $j$, which are estimated in the initial step, such as using (1) and (2). The parameter $\widehat{\gamma}_{i s}^{0}, \widehat{\gamma}_{i s}$ and $\widehat{\phi}_{j s}$ are estimated by Kalman filter method. Technical details are specified in appendix.

\section{Model Estimation}

The VAR approximating model of default intensity factor connectedness has a natural state-space model representation. If we pool all the banks together, the measurement 
and transition equations are

$$
\begin{aligned}
& Y_{t}=H X_{t}+v_{t} \\
& X_{t}=F X_{t-1}+\varepsilon_{t}
\end{aligned}
$$

where

$$
Y_{t}=\left(\begin{array}{c}
y_{1 t}\left(\tau_{1}\right) \\
y_{1 t}\left(\tau_{2}\right) \\
\vdots \\
y_{N t}\left(\tau_{k}\right)
\end{array}\right)_{(N k \times 1)}, X_{t}=\left(\begin{array}{c}
l_{1 t} \\
s_{1 t} \\
\vdots \\
c_{N t}
\end{array}\right)_{(3 N \times 1)}, v_{t}=\left(\begin{array}{c}
v_{1 t}\left(\tau_{1}\right) \\
v_{1 t}\left(\tau_{2}\right) \\
\vdots \\
v_{N t}\left(\tau_{k}\right)
\end{array}\right)_{(N k \times 1)}, \varepsilon_{t}=\left(\begin{array}{c}
\varepsilon_{1 t}^{l} \\
\varepsilon_{1 t}^{s} \\
\vdots \\
\varepsilon_{N t}^{c}
\end{array}\right)_{(3 N \times 1)}
$$

and

$H=\left(\begin{array}{ccccccc}1 & \frac{1-\exp \left(-\delta_{1} \tau_{1}\right)}{\delta_{1} \tau_{1}} & \frac{1-\exp \left(-\delta_{1} \tau_{1}\right)}{\delta_{1} \tau_{1}}-\exp \left(-\delta_{1} \tau_{1}\right) & \cdots & 0 & 0 & 0 \\ 1 & \frac{1-\exp \left(-\delta_{1} \tau_{2}\right)}{\delta_{1} \tau_{2}} & \frac{1-\exp \left(-\delta_{1} \tau_{2}\right)}{\delta_{1} \tau_{2}}-\exp \left(-\delta_{1} \tau_{2}\right) & \cdots & 0 & 0 & 0 \\ \vdots & \vdots & \vdots & \vdots & \vdots & \vdots & \vdots \\ 0 & 0 & 0 & \cdots & 1 & \frac{1-\exp \left(-\delta_{N} \tau_{k}\right)}{\delta_{N} \tau_{k}} & \frac{1-\exp \left(-\delta_{N} \tau_{k}\right)}{\delta_{N} \tau_{k}}-\exp \left(-\delta_{N} \tau_{k}\right)\end{array}\right)_{(N k \times 3 N)}$

Meanwhile, when level, slope and curvature factors are orthogonal with autoregressive process of order one, the parameter matrix $F$ is,

$$
F=\left(\begin{array}{cccccccccc}
\alpha_{11}^{l} & 0 & 0 & \alpha_{12}^{l} & 0 & 0 & \cdots & \alpha_{1 N}^{l} & 0 & 0 \\
0 & \alpha_{11}^{s} & 0 & 0 & \alpha_{12}^{s} & 0 & \cdots & 0 & \alpha_{1 N}^{s} & 0 \\
\vdots & \vdots & \vdots & \vdots & \vdots & \vdots & \cdots & \vdots & \vdots & \vdots \\
0 & 0 & \alpha_{N 1}^{c} & 0 & 0 & \alpha_{N 2}^{c} & \cdots & 0 & 0 & \alpha_{N N}^{c}
\end{array}\right)_{(3 N \times 3 N)}
$$

which accommodates (2), (5), (6), and (7).

We introduce a two-step estimation method that couples the DNS model with the variance decomposition technique: In the first step, we estimate the dynamic level factor $l_{i t}$, the slope factor $s_{i t}$, and the curvature factor $c_{i t}$ for each bank $i$ through the Kalman filter estimation of the state space model, based on equation (1) and (2); In the second step, by utilizing the network framework based on variance decomposition in Diebold and Ylmaz (2014), we investigate the dynamics of LT, ST and MT default factors in a network perspective, based on equation (3). In order to uncover the dynamics of the network connectedness, we use a rolling window estimation for the each factors. 


\section{Data}

We firstly discuss the information content of CDS spreads that provides the theoretical foundations for using CDS, and then perform preliminary analysis to support the motivations in the subsequent study.

\subsection{Implied default intensity in CDS spreads}

The basic pricing formula for CDS contracts is to achieve the payoff balance between CDS buyers and CDS sellers. Consider a CDS contract with the maturity of $M$ years and quarterly premium payments. $C D S_{t}(M)$ denotes the annualized spread at issue. $L$ is the risk-neutral expected loss of the notional value in the event of default. We normalize the notional face value of the contract as $1 . \lambda_{t}$ denotes the risk-neutral arrival rate of a credit event, i.e., default intensity. Then, at issue, the present value of CDS-provider side and that of CDS-buyer side should be equal,

$$
\frac{1}{4} C D S_{t}(M) \sum_{j=1}^{4 M} \mathrm{E}_{t}\left[\exp \left\{-\int_{t}^{t+j / 4}\left(r_{s}+\lambda_{s}\right) d s\right\}\right]=L \int_{t}^{t+M} \mathrm{E}_{t}\left[\lambda_{u} \exp \left\{-\int_{t}^{u}\left(r_{s}+\lambda_{s}\right) d s\right\}\right] d u
$$

where $r_{t}$ is the risk free rate. Pan and Singleton (2008) assumed the $s$ years time discount factor as $\delta(s)=\exp \left(-\int_{t}^{t+s} r_{u} d u\right)$, and presumed the conditional survival probability $q(s)$ follows

$$
q(s)=\exp \left(-\lambda_{t} s\right)
$$

Then 21$)$ is transformed to

$$
\frac{1}{4} C D S_{t}(M) \sum_{j=1}^{4 M} \mathrm{E}_{t}\left\{\delta\left(\frac{j}{4}\right) q\left(\frac{j}{4}\right)\right\}=L \sum_{j=1}^{4 M} \mathrm{E}_{t}\left[\delta\left(\frac{j}{4}\right)\left\{q\left(\frac{j-1}{4}\right)-q\left(\frac{j}{4}\right)\right\}\right]
$$

Combing 23) and 22), we can directly imply the default intensity from CDS spreads,

$$
\lambda_{t}=4 \log \left\{1+\frac{C D S_{t}(M)}{4 L}\right\}
$$


It is noteworthy that the explicit relationship between default intensity and CDS spreads, such as in (24), is only satisfied under certain assumptions, such as constant loss given default $L$, and survival probability $q(s)$ in $(22)$. Since implied default intensity is naturally dependent on predetermined model set-up, we thoroughly focus on CDS spreads as a direct indicator of default intensity (see Equation (24)), to get rid of the potential model misspecification risk. Besides, through CDS spreads investigation, it also permits us to perform an out-of-sample forecast and practice a convenient comparison.

\subsection{CDS spreads data}

We draw our attention to the CDS spreads belonging to the Top 10 of the global systemically important banks (G-SIBs), i.e., $N=10$, for their plenty maturities in CDS contracts. In Table 2, the CDS spreads with maturities ranging from 6 months, 1, 2, 3, 4, 5, 7, 10, 20, 30 years are available via DataStream. These 10 banks are selected out of the thirty-four G-SIBs based on the availability of sufficient maturities of CDS. Banks with less than the 10 maturities of CDS are excluded from the study to ensure the representative ability of latent factors. The sample period is selected from January 1st, 2008 to December 31th, 2015, at daily frequency.

Table 2: Banks

\begin{tabular}{r|lll}
\hline \hline & Institution & Ticker & Country \\
\hline 1 & Bank of America & BAC & United States \\
2 & Citygroup & C & United States \\
3 & Goldman Sachs & GS & United States \\
4 & J.P.Morgan & JPM & United States \\
5 & Wells Fargo & WFC & United States \\
6 & Deutsche Bank & DB & Germany \\
7 & Commerzbank & CBG & Germany \\
8 & Barclays Bank & BCS & United Kingdom \\
9 & HSBC Bank & HBC & United Kingdom \\
10 & UBS & UBS & Switzerland \\
\hline \hline
\end{tabular}

Figure 1 depicts a 3D plot of the time-varying CDS spread curves of Goldman Sachs and HSBC Bank. The display of the CDS curves for the banks is depicted in Figure 10 in Appendix. The CDS curves display apparently substantial level movements across time, 
and they also exhibit a clear commonality to support the notion of credit comovement. One can observe a simultaneous increase of credit curve into banks during the Eurozone debt crisis periods, which motivates us to analyse the connectedness across banks.
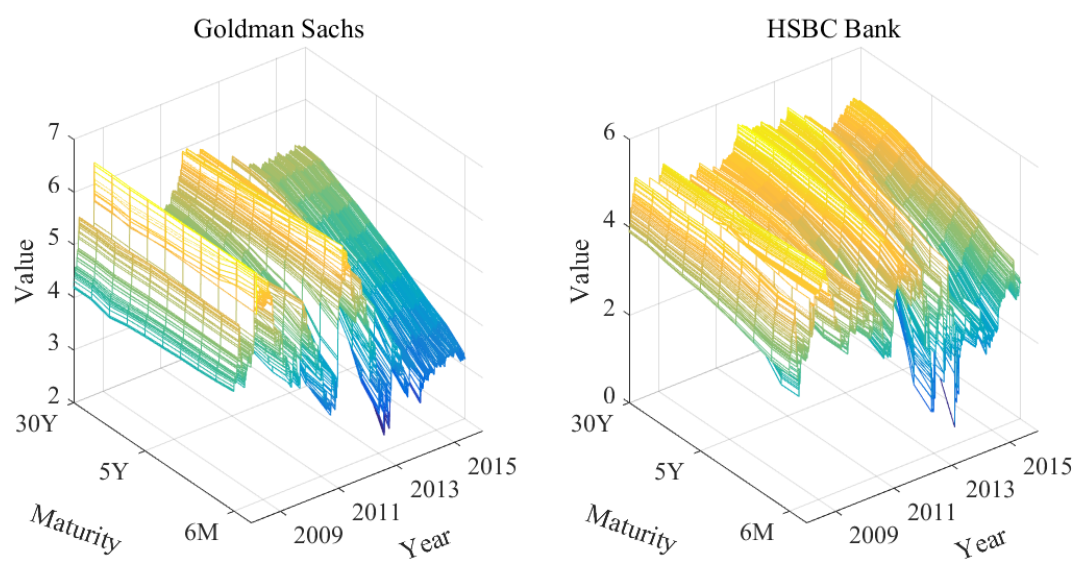

Figure 1: CDS spreads data

Note: (log) Credit default swap spreads 2008.01.01 - 2015.12.31 with daily data for Goldman Sachs and HSBC Bank across 10 maturities. The data in our study is after logarithm transformation.

Q DDINetwork_CDS

\subsection{Preliminary analysis of CDS spreads}

In summary, there are 26 free parameters to be estimated: the $3 \times 3$ transition matrix of the three state variables containing 9 free parameters, the mean state variables containing 3 free parameters, the 1 decay parameter in measurement equation, the diagonal of disturbance covariance matrix of transition equation containing 10 free parameters with each covariance for the counterpart of 10 maturities of CDS spreads, and the 3 free parameters constituting from the diagonal of measurement disturbance covariance matrix with each for one of the 3 latent variables.

We use the Kalman filter to derive the state variables and CDS spreads of next stage, after which we proceed to evaluate the unknown parameters with the maximum likelihood estimation under Gaussian distribution assumptions for the disturbance of measurement and transition equations. The initial parameter values are obtained by using the Diebold-Li two-step ordinary least squares regression and the startup value for the decay parameter is 0.0609 . The estimated decay parameters are varying across banks

Table 3 reports summary statistics for the estimated DNS factors, which will be used 
Long-run factor: Level

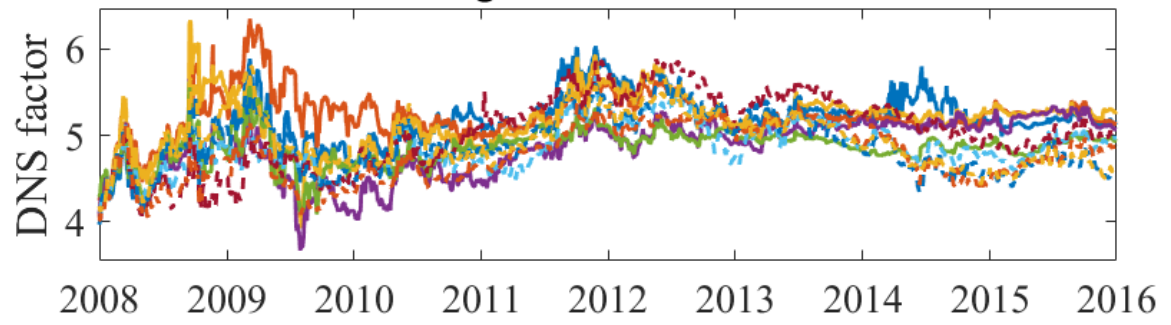

Short-run factor: Slope
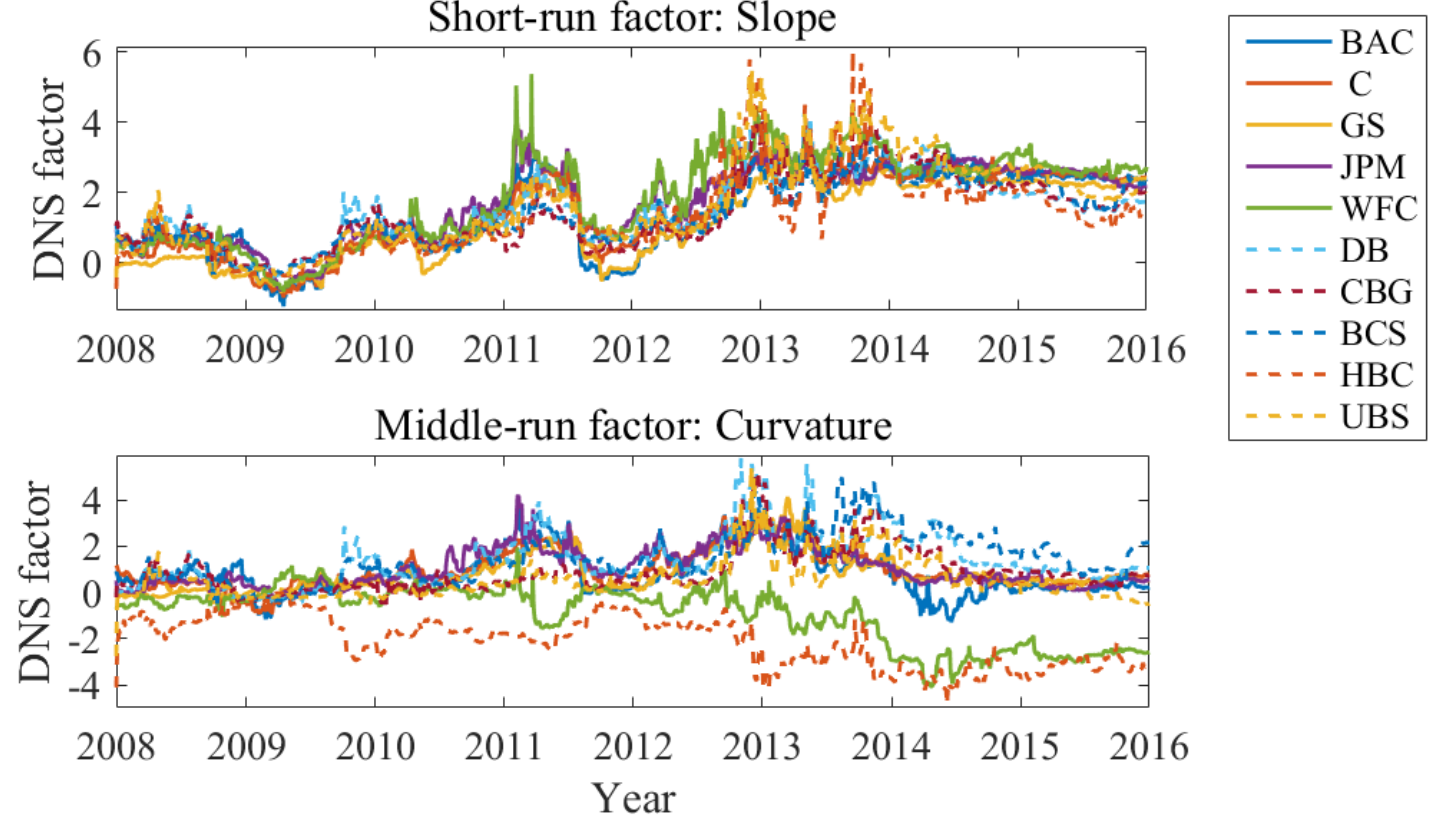

Figure 2: DNS factors

Note: Data period: 2008.01.01 - 2015.12.31 with daily data. The upper panel collects the level factors, middle panel for the slope factors, and the bottom panel for the curvature factors.

Q DDINetwork_network_static 
Table 3: Descriptive statistics for the estimated DNS factor.

\begin{tabular}{|c|c|c|c|c|c|c|}
\hline Factor & Mean & Std.dev. & Min & Max & $\overline{\rho \rho(5)}$ & $\overline{\rho \rho(10)}$ \\
\hline \multicolumn{7}{|c|}{ Bank of America } \\
\hline$l_{t}$ & 5.156 & 0.327 & 3.962 & 6.039 & 0.920 & 0.867 \\
\hline$s_{t}$ & -1.475 & 1.160 & -3.613 & 1.181 & 0.989 & 0.976 \\
\hline$c_{t}$ & 0.894 & 0.921 & -1.150 & 3.414 & 0.976 & 0.946 \\
\hline \multicolumn{7}{|c|}{ Citygroup } \\
\hline$l_{t}$ & 5.242 & 0.270 & 4.273 & 6.379 & 0.891 & 0.827 \\
\hline$s_{t}$ & -1.486 & 1.146 & -3.731 & 0.944 & 0.989 & 0.978 \\
\hline$c_{t}$ & 1.040 & 0.799 & -0.823 & 3.276 & 0.972 & 0.944 \\
\hline \multicolumn{7}{|c|}{ Goldman Sachs } \\
\hline$l_{t}$ & 5.175 & 0.323 & 3.867 & 6.498 & 0.914 & 0.854 \\
\hline$s_{t}$ & -1.207 & 1.123 & -3.273 & 0.914 & 0.989 & 0.977 \\
\hline$c_{t}$ & 0.751 & 0.822 & -0.497 & 3.817 & 0.976 & 0.949 \\
\hline \multicolumn{7}{|c|}{ J.P.Morgan } \\
\hline$l_{t}$ & 4.841 & 0.329 & 3.651 & 5.631 & 0.951 & 0.916 \\
\hline$s_{t}$ & -1.717 & 1.029 & -3.736 & 0.738 & 0.985 & 0.971 \\
\hline$c_{t}$ & 1.198 & 0.817 & -0.083 & 4.275 & 0.966 & 0.932 \\
\hline \multicolumn{7}{|c|}{ Wells Fargo } \\
\hline$l_{t}$ & 4.841 & 0.197 & 4.067 & 5.621 & 0.868 & 0.777 \\
\hline$s_{t}$ & -1.868 & 1.232 & -5.051 & 0.718 & 0.977 & 0.959 \\
\hline$c_{t}$ & -0.932 & 1.228 & -3.984 & 1.453 & 0.985 & 0.969 \\
\hline \multicolumn{7}{|c|}{ Deutsche Bank } \\
\hline$l_{t}$ & 4.864 & 0.267 & 4.151 & 5.754 & 0.930 & 0.880 \\
\hline$s_{t}$ & -1.558 & 0.974 & -4.344 & 0.420 & 0.975 & 0.953 \\
\hline$c_{t}$ & 1.405 & 1.054 & -0.589 & 5.226 & 0.954 & 0.916 \\
\hline \multicolumn{7}{|c|}{ Commerzbank } \\
\hline$l_{t}$ & 5.027 & 0.439 & 3.927 & 5.898 & 0.966 & 0.945 \\
\hline$s_{t}$ & -1.436 & 0.997 & -3.893 & 0.307 & 0.984 & 0.969 \\
\hline$c_{t}$ & 0.996 & 0.885 & -0.361 & 4.757 & 0.965 & 0.932 \\
\hline \multicolumn{7}{|c|}{ Barclays Bank } \\
\hline$l_{t}$ & 4.933 & 0.353 & 4.048 & 5.764 & 0.938 & 0.902 \\
\hline$s_{t}$ & -1.394 & 0.908 & -3.464 & 0.385 & 0.979 & 0.959 \\
\hline$c_{t}$ & 1.345 & 0.934 & -0.480 & 4.166 & 0.955 & 0.912 \\
\hline \multicolumn{7}{|c|}{ HSBC Bank } \\
\hline$l_{t}$ & 4.778 & 0.321 & 3.948 & 5.329 & 0.972 & 0.945 \\
\hline$s_{t}$ & -1.381 & 1.014 & -6.551 & 0.180 & 0.931 & 0.887 \\
\hline $\begin{array}{l}c_{t} \\
\text { UBS }\end{array}$ & -2.058 & 1.194 & -6.017 & 0.472 & 0.959 & 0.927 \\
\hline$l_{t}$ & 4.819 & 0.325 & 4.023 & 5.819 & 0.946 & 0.891 \\
\hline$s_{t}$ & -1.540 & 1.101 & -4.462 & 0.305 & 0.983 & 0.965 \\
\hline$c_{t}$ & 1.585 & 1.295 & -0.277 & 6.928 & 0.964 & 0.927 \\
\hline
\end{tabular}

Note: $\rho(5)$ and $\rho(10)$ denote the autocorrelation coefficients with the lag of 5 or 10 periods.

Q DDINetwork_network_static 
in the subsequent network analysis. The level factors present least variance compared with the slope and curvature factors. The factor autocorrelations reveal that all factors display persistent dynamics, with the level more persistent than the slope. Although the level, the slope and the curvature factors behave distinctly, they clearly display a certain degrees of similarity across banks, as shown in Figure 2.

The basis for the network analysis is the possible existence of co-movements in the factor dynamics across banks, implying the exist of potential spillover effects or underlying transmission mechanism. To investigate this, we plot the estimated factors for all banks in Figure 2. The upper, middle and bottom panel present the level, the slope and the curvature factor, respectively. To visualize the difference across the banks in the US and Europe, we feature the factors of 5 US banks with solid line, while the counterparts of European banks in dashed line. Figure2 reveals clear evidence of co-movements in factors dynamics, especially for the level and slope factor. One can observe that the slope/ST factors across 10 G-SIBs have climbed since the outbreak of the European debt crisis, indicating possible inverted credit curves (downward slope curves).

\section{$5 \quad$ Empirical results}

To characterize the evolution of the default risk connectedness among the US and European banks, we proceed to a four steps analysis: we firstly perform a full-sample analysis separately for level, slope, and curvature factor, to assess the unconditional or average connectedness. After this static connectedness analysis, a rolling-window sample analysis is conducted for the three factors respectively, to portray the dynamics of conditional connectedness. By doing so, one can monitor the dynamics of spillover effect between the US and European banks over time. Using the total connectedness in the rolling-sample framework as an indicator of systematic default risk, we analyse the sources of the systematic risk. Finally, having the predefined connectedness among bank default risk, we report the forecasting performance when incorporating the factors from other banks. 


\subsection{Network: static}

Systemic risk is not easy to define, but the universally accepted characteristics are that it has large impact; is widespread, and has a ripple effect that endangers the financial system. Network analysis enables us to cover three major concepts of systemic risk by portraying the interplay among financial institutions, measuring their interconnectedness and quantifying the spillover effect.

Interconnectedness of financial institutions on the interbank market is an absolute key to understanding systemic risk. Interconnectedness captures the situations when financial distress in one institution subsequently raises the likelihood of financial distress in other institutions because of their network of contractual relations and interbank lending among them, leading to a 'too-interconnected-to-fail' situation. The resulting connectedness parameters like $C$ from $(13)$, therefore, can be used to monitor systemic vulnerability.

In the following analysis, we examine the interconnectedness and spillover with respect to the default factors in the ST, MT and LT perspective. This effort can help to answer the questions e.g. Will credit spillover or contagion evenly be observed in the short-term and long-term credit horizon? Can we use this information to foresee crisis and evaluate the tension embedded in the credit assets with different maturities?

\subsubsection{Level factor}

Table 4 reports the full-sample connectedness of level factors. As the level factors capture the long-term component of CDS spreads, the entries in Table 4 turn to be the long-term directional connectedness measures. Many features are revealed. Blocks of high pairwise directional connectedness are notable, especially for the US banks. The values in the first five columns, which captures the spillover effect contributed to the US banks, are apparently higher than that of European banks. The total connectedness for level factor is on average $85.50 \%$. In addition, the 'From' degree distribution is noticeably less volatile than the 'To' degree distribution in the case of the US group, but it is not a case for the EU group. Through this table, one can find the US banks are exporting LT default risk to the EU ones. 
Table 4: Static Connectedness: Level factor

\begin{tabular}{l|rrrrrrrrrrr}
\hline \hline & BAC & C & GS & JPM & WFC & DB & CBG & BCS & HBC & UBS & FROM \\
\hline BAC & 19.95 & 14.00 & 13.27 & 12.39 & 12.84 & 6.79 & 5.01 & 5.27 & 5.06 & 5.43 & 80.05 \\
C & 16.85 & 17.91 & 14.13 & 13.05 & 13.47 & 5.98 & 4.14 & 4.76 & 4.65 & 5.05 & 82.09 \\
GS & 16.46 & 18.54 & 20.03 & 14.03 & 14.95 & 3.58 & 2.39 & 2.74 & 3.48 & 3.81 & 79.97 \\
JPM & 17.42 & 17.73 & 16.22 & 15.67 & 15.17 & 4.12 & 2.96 & 3.11 & 3.76 & 3.83 & 84.33 \\
WFC & 16.16 & 16.35 & 15.05 & 14.57 & 15.88 & 5.27 & 3.81 & 3.96 & 4.38 & 4.56 & 84.12 \\
DB & 11.82 & 13.05 & 12.26 & 11.61 & 11.06 & 12.28 & 6.50 & 7.02 & 6.96 & 7.45 & 87.72 \\
CBG & 10.29 & 10.84 & 10.84 & 9.81 & 9.47 & 12.29 & 12.49 & 8.26 & 7.58 & 8.13 & 87.51 \\
BCS & 8.84 & 10.46 & 10.22 & 9.57 & 8.99 & 12.97 & 8.40 & 12.71 & 8.55 & 9.29 & 87.29 \\
HBC & 11.37 & 12.94 & 12.45 & 11.48 & 11.10 & 10.05 & 7.05 & 8.12 & 7.88 & 7.56 & 92.12 \\
UBS & 11.27 & 12.57 & 11.74 & 10.89 & 10.40 & 10.45 & 6.03 & 8.98 & 7.44 & 10.23 & 89.77 \\
\hline TO & 120.47 & 126.48 & 116.17 & 107.40 & 107.44 & 71.49 & 46.30 & 52.23 & 51.87 & 55.11 & 85.50 \\
NET & 40.42 & 44.39 & 36.20 & 23.07 & 23.33 & -16.23 & -41.22 & -35.07 & -40.25 & -34.65 & - \\
\hline \hline
\end{tabular}

Note: Data period: 2008.01.01 - 2015.12.31 with daily data.

Q DDINetwork_network_static

Let us discuss some of the features of the long-term connectedness table in more detail.

The highest observed pairwise connectedness is from C to GS $\left(C_{G S \leftarrow C}=18.54 \%\right)$, while in return, the pairwise connectedness from GS to $\mathrm{C}\left(C_{C \leftarrow G S}\right)$ is slightly small $14.13 \%$. The next highest pairwise connectedness is from C to JPM $\left(C_{J P M \leftarrow C}=17.73 \%\right)$, which is slightly higher than the pairwise connectedness from BAC to JPM $\left(B A C_{J P M \leftarrow C}=\right.$ 17.42\%). The bank $\mathrm{C}$ has the largest market capitalization before the 2008 financial crisis periods, it is reasonable that the total connectedness to others are largest. The bank with bigger market capitalization is more capable of offering interbank loans to other banks, it is so-called 'too big to fail'. On the other hand, the long-term pairwise directional connectedness among European banks is relatively smaller (less than 10\%), except a few relatively large measures from DB to BCS $\left(C_{B C S \leftarrow D B}=12.97 \%\right)$, and from DB to $\mathrm{CBG}\left(C_{C B G \leftarrow D B}=12.29 \%\right)$.

The 'From' column is the row sum of the pairwise connectedness except the own-effects (diagonal elements of the matrix). It reveals the total directional connectedness from others to each of the ten banks. In other words, it captures the contribution of credit shocks resulting from other banks to the total variance of the forecast error of bank $i$. While the total directional connectedness is distributed tightly, the 'From' effects of US banks appear consistently smaller than that of the European banks, showing that the US banks are less impacted by the EU credit shocks. 
The column sum of pairwise connectedness quantify the spillover effect of bank $i$ to others. By definition, each bank's share in the forecast error variance of others is not compulsorily to add up to 1, therefore, elements in the 'To' row can exceed 100\%. 'To' effect varies over banks, ranging from $126 \%$ to $46 \%$. The largest commercial banks (as of 2008) were the ones that have the highest values of connectedness to others. C generated the largest default transmission, $126 \%$, to others. This is consistent with the findings in Diebold and Yllmaz (2014), which is based on the volatility of stock returns among US financial institutes. Besides, the five US banks all generate significant (exceeding 100\%) long-term default risk spillover to others, compared with European banks, which evidently imply the transmission of long-term default risk shocks from the US financial institutions to the European counterparts.

Further, the strong spillover effects between the connectedness of US and European banks are clearly observed in their 'Net' row. The difference between the total directional connectedness to others and the total directional from others results in the net total directional connectedness to others. C leads the highest net total directional connectedness (44.39\%), followed by BAC (40.42\%), with other positive effects of US banks. By contrast, the values of net total directional connectedness in European banks are significantly negative, indicating that the contributions of European banks shock to other banks' forecast error variance are generally trivial in term of the long run default risk.

\subsubsection{Slope factor}

The short-term connectedness is shown in Table 5. The highest observed directional connectedness is $C_{J P M \leftarrow H B C}=33.71 \%$, followed by $C_{C B G \leftarrow H B C}=22.48 \%$. Being one of the most vulnerable banks during the European debt crisis, HSBC Bank clearly spreads its tail stress to other banks.

One observes above that Bank of America is weakly effected by the shocks from others, with only $C_{B A C \leftarrow .}=53.35 \%$. Although in the short run, banks in the same region still have relatively large connectedness compared with the cross-region connectedness, little evidence of a consistent spillover effects from US to Europe as we have found in the long-run investigation. Different from Table 4. HBC creates the strongest risk spillover, 
Table 5: Static Connectedness: Slope factor

\begin{tabular}{l|rrrrrrrrrrr}
\hline \hline & BAC & C & GS & JPM & WFC & DB & CBG & BCS & HBC & UBS & FROM \\
\hline BAC & 46.65 & 11.91 & 8.89 & 7.71 & 4.36 & 4.94 & 4.66 & 2.97 & 4.20 & 3.72 & 53.35 \\
C & 12.66 & 15.97 & 7.80 & 9.58 & 9.54 & 8.19 & 6.87 & 7.91 & 16.05 & 5.44 & 84.03 \\
GS & 12.20 & 14.42 & 9.73 & 11.00 & 9.83 & 9.74 & 7.55 & 7.87 & 10.72 & 6.93 & 90.27 \\
JPM & 7.00 & 8.76 & 3.72 & 12.13 & 6.42 & 10.56 & 5.48 & 8.52 & 33.71 & 3.70 & 87.87 \\
WFC & 10.08 & 13.86 & 6.86 & 13.84 & 17.56 & 8.27 & 6.26 & 7.12 & 10.68 & 5.48 & 82.44 \\
DB & 8.04 & 10.09 & 5.74 & 9.11 & 6.73 & 21.65 & 10.49 & 10.29 & 9.18 & 8.67 & 78.35 \\
CBG & 6.71 & 8.88 & 4.34 & 9.00 & 12.05 & 10.43 & 10.56 & 8.14 & 24.48 & 5.40 & 89.44 \\
BCS & 6.86 & 8.93 & 5.14 & 7.67 & 5.07 & 17.13 & 13.26 & 17.49 & 8.59 & 9.86 & 82.51 \\
HBC & 3.04 & 3.73 & 2.07 & 3.41 & 3.00 & 15.07 & 9.32 & 13.14 & 39.23 & 8.00 & 60.77 \\
UBS & 6.22 & 8.11 & 4.53 & 7.16 & 5.41 & 15.48 & 11.06 & 12.36 & 17.83 & 11.85 & 88.15 \\
\hline TO & 72.81 & 88.67 & 49.09 & 78.48 & 62.41 & 99.81 & 74.95 & 78.31 & 135.43 & 57.21 & 79.72 \\
NET & 19.46 & 4.64 & -41.18 & -9.39 & -20.02 & 21.45 & -14.49 & -4.20 & 74.67 & -30.94 & - \\
\hline \hline
\end{tabular}

Note: Data period: 2008.01.01 - 2015.12.31 with daily data.

Q DDINetwork_network_static

followed by DB, both were seriously hit especially during the European debt crisis. Consistently, in terms of 'Net' connectedness measures, HBC leads the head, 74.67\%, while the next highest is from DB. Besides the positive values of $\mathrm{BAC}$ and $\mathrm{C}$, the negative values are generated from other banks. In the end, the total connectedness is $79.72 \%$, which is slightly smaller than $85.50 \%$ derived in the long-term total connectedness.

\subsubsection{Curvature factor}

Table 6: Static Connectedness: Curvature factor

\begin{tabular}{l|rrrrrrrrrrr}
\hline \hline & BAC & C & GS & JPM & WFC & DB & CBG & BCS & HBC & UBS & FROM \\
\hline BAC & 22.08 & 10.89 & 6.26 & 6.82 & 1.19 & 16.77 & 9.25 & 10.36 & 0.18 & 16.20 & 77.92 \\
C & 6.40 & 19.77 & 7.55 & 8.62 & 1.73 & 16.19 & 9.16 & 14.00 & 2.64 & 13.94 & 80.23 \\
GS & 10.83 & 18.24 & 14.09 & 9.34 & 3.53 & 15.65 & 7.11 & 8.35 & 3.77 & 9.10 & 85.91 \\
JPM & 14.59 & 17.26 & 4.77 & 31.00 & 7.07 & 5.12 & 3.82 & 5.56 & 6.62 & 4.19 & 69.00 \\
WFC & 5.47 & 4.60 & 0.76 & 8.19 & 40.90 & 1.40 & 0.69 & 1.69 & 33.18 & 3.13 & 59.10 \\
DB & 1.50 & 5.91 & 3.35 & 4.34 & 0.33 & 52.11 & 10.00 & 11.48 & 2.57 & 8.39 & 47.89 \\
CBG & 0.68 & 2.17 & 1.16 & 1.18 & 0.10 & 17.45 & 40.38 & 10.49 & 5.35 & 21.03 & 59.62 \\
BCS & 1.10 & 5.07 & 2.60 & 3.53 & 0.23 & 27.17 & 13.86 & 29.46 & 0.12 & 16.86 & 70.54 \\
HBC & 0.12 & 2.83 & 2.80 & 1.55 & 0.11 & 1.71 & 0.53 & 2.10 & 84.39 & 3.85 & 15.61 \\
UBS & 0.83 & 5.29 & 3.53 & 3.35 & 0.09 & 20.97 & 12.03 & 17.13 & 0.35 & 36.41 & 63.59 \\
\hline TO & 41.52 & 72.26 & 32.78 & 46.92 & 14.38 & 122.44 & 66.45 & 81.17 & 54.77 & 96.69 & 62.94 \\
NET & -36.40 & -7.97 & -53.12 & -22.09 & -44.72 & 74.55 & 6.84 & 10.64 & 39.17 & 33.10 & - \\
\hline \hline
\end{tabular}

Note: Data period: 2008.01.01 - 2015.12.31 with daily data.

Q DDINetwork_network_static

The middle term directional connectedness is summarized in Table 6. The total connect- 
edness, $62.94 \%$, is obviously smaller than the short term and long term connectedness. In terms of the pairwise directional connectedness, the values vary more widely, such as the highest observed connectedness measure is from HBC to WFC $\left(C_{W F C \leftarrow H B C}=33.18 \%\right)$ while in the return, the lowest one from WFC to $\mathrm{HBC}\left(C_{H B C \leftarrow W F C}=0.09 \%\right)$ is nearly zero. The spillover effect in this case is obviously 'asymmetric'. In the case of DB, one can find its spillover power in the MT or ST, but not in LT (see Table 4). The default tensions emphasizing on ST and MT imply that DB may hold more short-run risky loans which endangers its short-run credit. Interestingly, the 'Net' directional connectednesses are uniformly positive among European banks compared with the consistent negative ones in the US.

In a nutshell, the three DNS factors and their connectedness convey information w.r.t the default risk at the particular credit horizons. For the bank like DB, the potential to have credit deterioration and subsequently create spillover to others is more likely to happen in the short term. However, in the longer term the credit condition becomes resilient and has constrictive transmission as shown through a reverse spillover in its level factor.

\subsection{Network: dynamics}

The DNS model coupled with a topological network can be seen as a means of monitoring systemic vulnerability. On the supervisory purpose, the updated assessment is even more demanded. For this purpose, one studies the dynamics of connectedness in which credit contagion can therefore be identified in time. Accordingly, they will be asked by Financial Stability Board (FSB) and Basel Committee on Banking Supervision (BCBS) for additional loss absorption capacities to ensure the sufficiency of their common equities in case of the default.

\subsubsection{Time-varying total connectedness}

Figure 3 presents time-varying connectedness, $C_{t}$, estimated via $C$ from (13) in a oneyear (260 observations) rolling window size. It reveals clear default risk cycles. In the LT perspective, the period of 2009 to middle-2014 exhibits a long lasting cycle, coinciding 
Long-run factor: Level
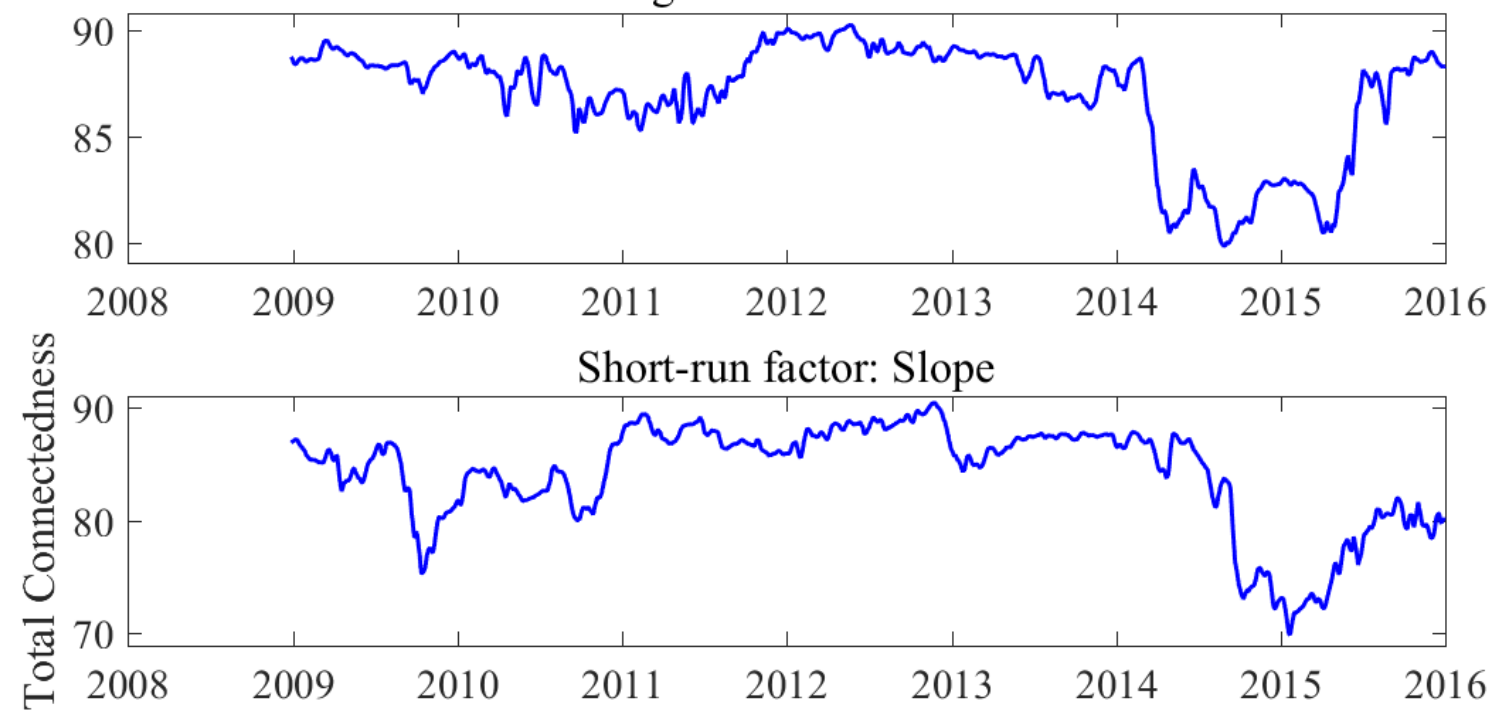

Middle-run factor: Curvature

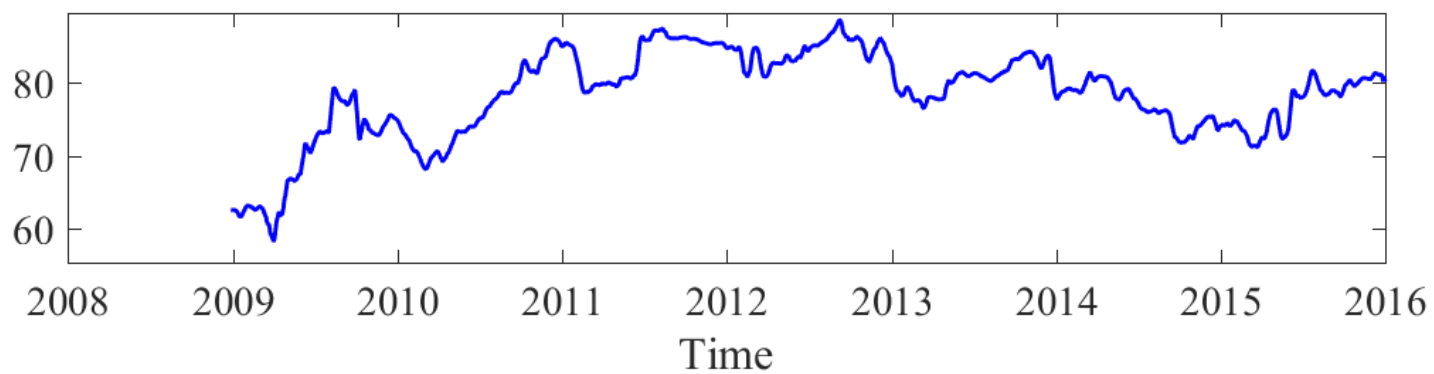

Figure 3: Rolling total connectedness

Note: Data period: 2009.01.01 - 2015.12.31 with daily data. The DNS factors and the corresponding dynamic of networks are computed by one-year rolling window estimation (260 observations). The variance decomposition is performed by the forecast horizon with 12 days. The red line denotes the smoothing line by one-week moving average. 
with the outbreak of European sovereign debt crisis. Despite short spells of recovery at the end of 2014, an increasing connectedness signals a upcoming systemic risk starting from middle-2015.

The long continuous cycle in the LT connectedness (upper panel) reveals similar patterns compared with the short term total connectedness by the slope factor (middle panel). The total connectedness declined from the high $90 \%$ to around $74 \%$ at the end of 2009 , followed by a raising period cycle of European debt crisis starting from end-2009 to beginning2011. It is a transmission cycle starting with the end of the previous disastrous 2007-08 financial crisis to signal an emerging European debt crisis. As the European debt crisis becomes widespread with a systemic danger, the short term total connectedness measures stick at the range of $85 \%-90 \%$ until the end of 2014. The banking industry suffered credit tension again as Chinese stock market became out of control in June, 2015. A third of the value of A-shares on the Shanghai Stock Exchange was lost within one month and intrigued a large collapse in global financial markets, leading to a concern on global economy stability again. The LT, ST and MT connectedness all reflect systemic fear in 2015 .

\subsubsection{Time-varying risk contribution}

Figure 4, Figure 5, and Figure 6 present the dynamics of individual default risk contribution to total directional connectedness, which are quantified by equation (12) for level factor, slope factor and curvature factor. One can interpret that bank $i$ has higher marginal risk contribution in the long-run default risk if the shock of level factor of bank $i$ contributes more on the forecasting errors of level factors of remaining banks. The upper panel depicts 'To' others, the middle panel displays 'From' others, and the bottom panel collects the 'Net' results. In each panel the five US banks lie in the first row while other five European banks are in the second row.

Except Bank of America, in Figure 4, the total directional connectedness 'To' others from US banks appears rising from 2008 until 2010, however, they show a downward trend after 2010. Conversely, the directional connectedness 'To' others from the five European banks tends to substantially rise up during the period of 2010-15. Overall, 

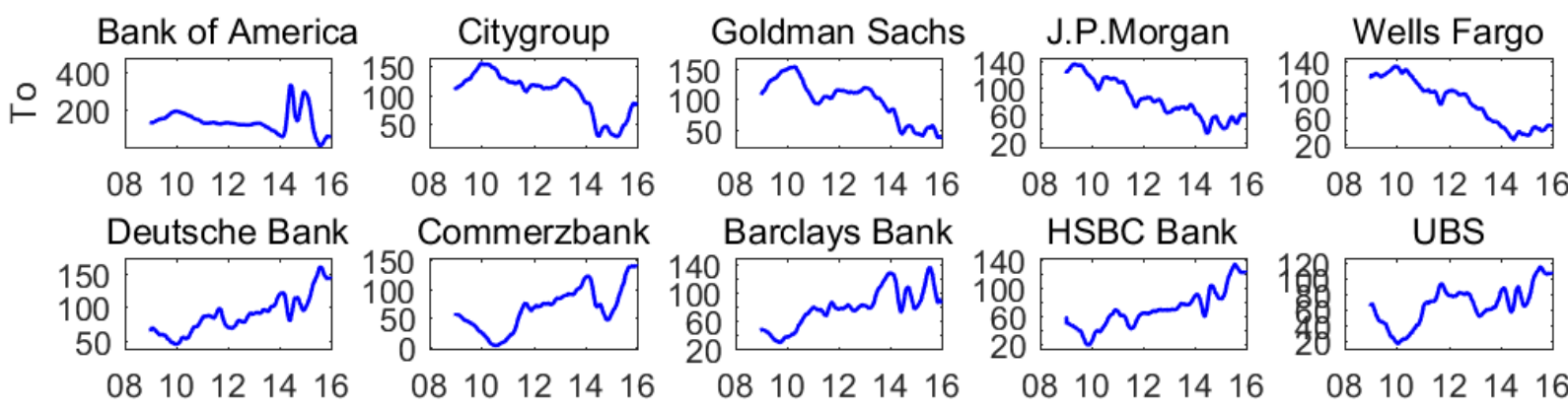

0810121416

Bank of America
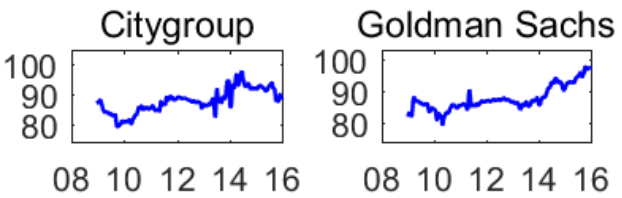

0810121416
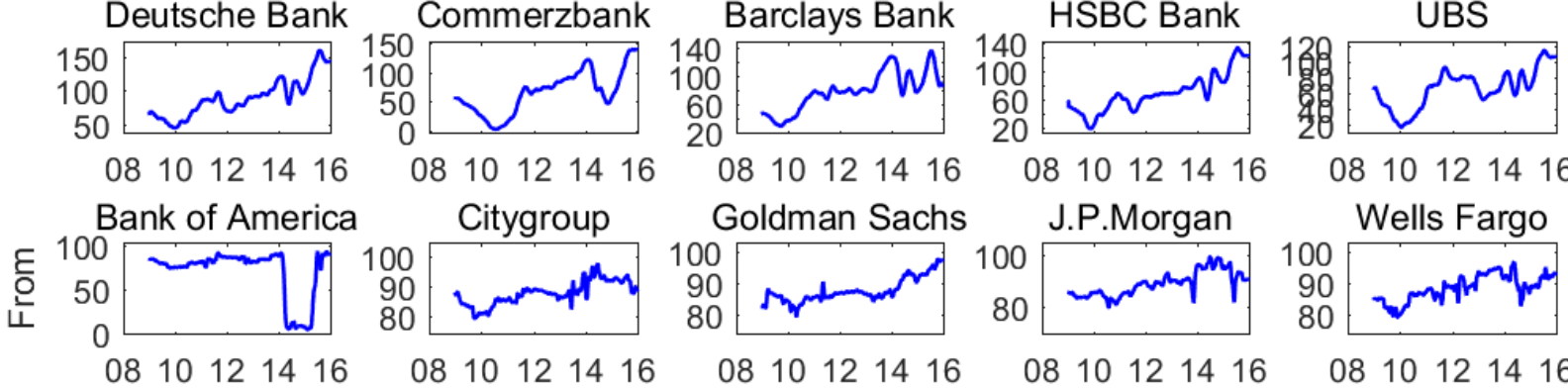

Deutsche Bank
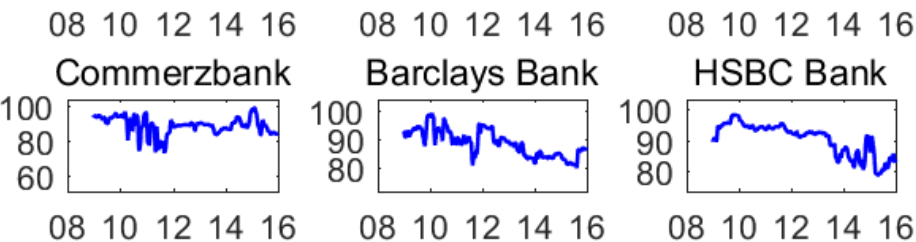

0810121416
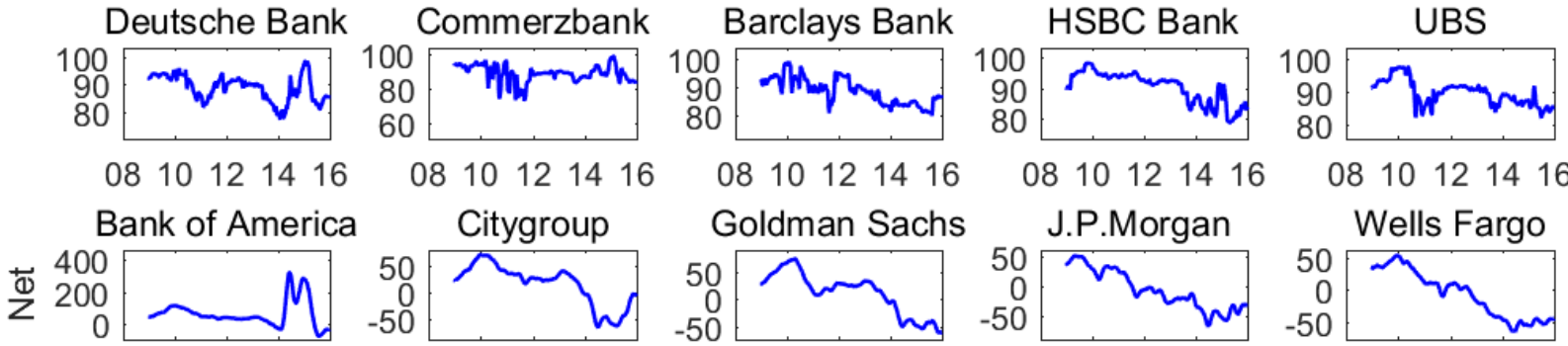

Goldman Sachs
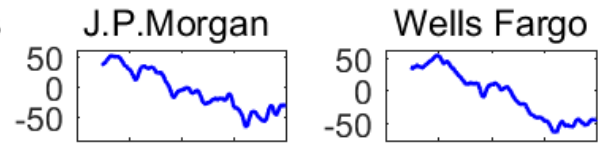

0810121416

0810121416

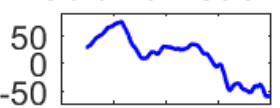

0810121416

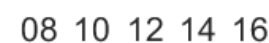

Deutsche Bank
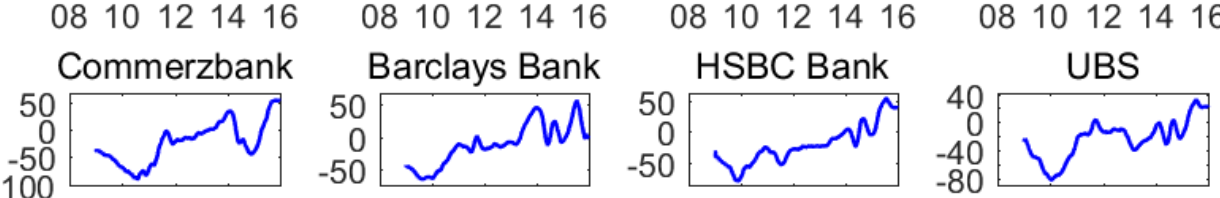

0810121416
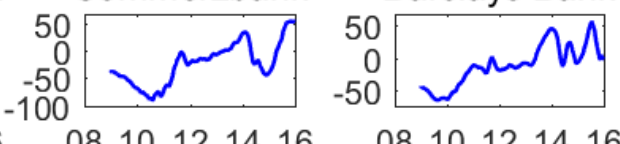

0810121416

$08 \quad 1012 \quad 14 \quad 16$

Figure 4: Rolling connectedness: level factors

Note: Data period: 2009.01.01 - 2015.12.31 with daily data. The DNS factors and the corresponding dynamic of networks are computed by one-year rolling window estimation (260 observations). The variance decomposition is performed by the forecast horizon with 12 days.

Q DDINetwork_network_dynamic 
the long-term default risk connectedness analysis documents a declined spillover effects from US banks to others, in return, the default risk shocks resulting in the forecast error variance are more and more remarkably transmitted from the European banks. This fact may reflect the effort of the US banking authority on supervisory after the outbreak of US subprime crisis.

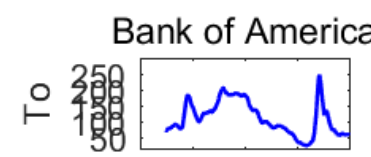

0810121416

Deutsche Bank

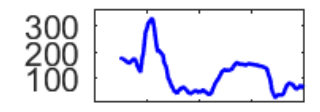

0810121416

Bank of America

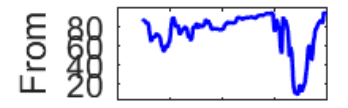

0810121416

Deutsche Bank

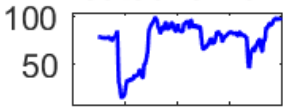

0810121416

Bank of America

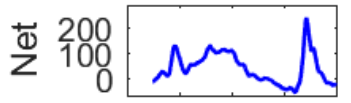

0810121416

Deutsche Bank

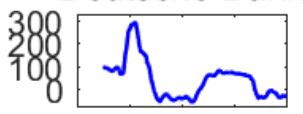

0810121416

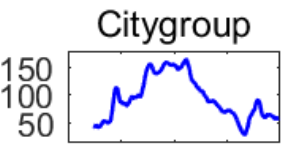

0810121416
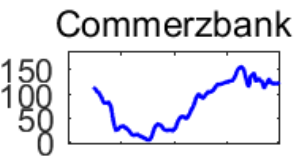

0810121416

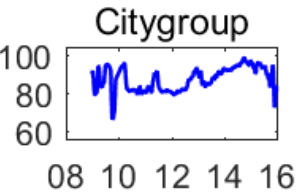

Commerzbank

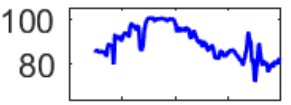

0810121416

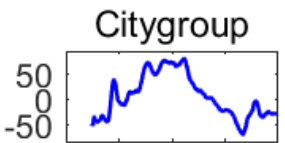

0810121416

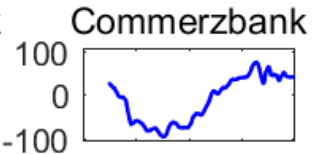

$08101214 \quad 16$

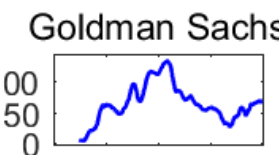

0810121416

Barclays Bank

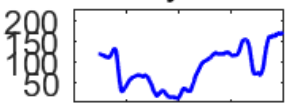

0810121416

Goldman Sachs

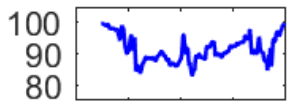

0810121416

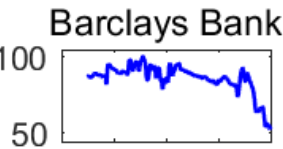

0810121416
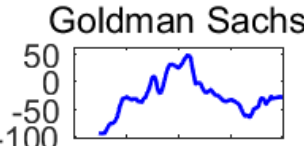

0810121416

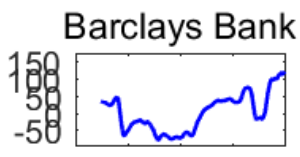

0810121416

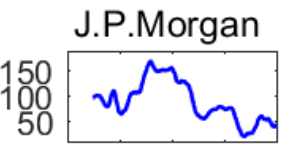

0810121416

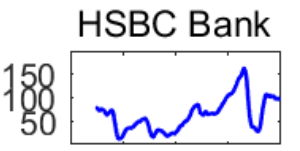

0810121416



0810121416

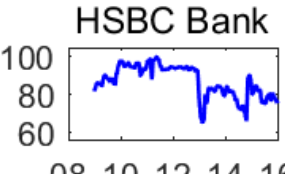

0810121416

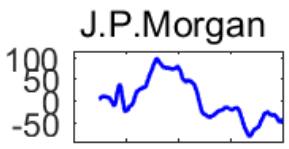

0810121416

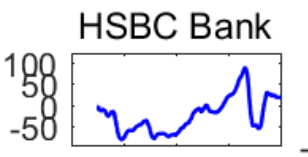

0810121416

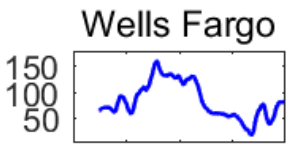

0810121416

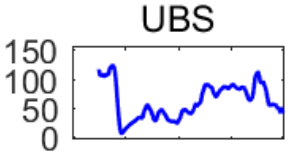

0810121416

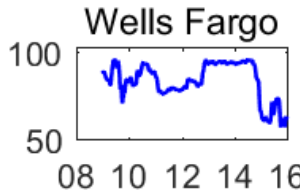

UBS

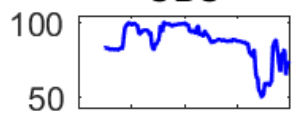

$08 \quad 10121416$

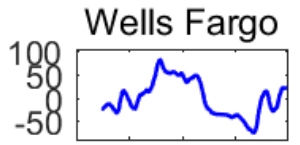

0810121416

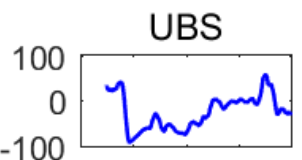

0810121416

Figure 5: Rolling connectedness: Slope

Note: Data period: 2009.01.01 - 2015.12.31 with daily data. The DNS factors and the corresponding dynamic of networks are computed by one-year rolling window estimation (260 observations). The variance decomposition is performed by the forecast horizon with 12 days.

Q DDINetwork_network_dynamic

Figure 5 reports a similar pattern of short term total directional connectedness dynamics.

In the short term default risk connectedness, the 'To' effect from US banks, except Bank of America, tend to fall roughly from 2012, after a rising trend during 2009-2012. In reverse, the short-term 'To' effect from European banks declined till 2012, subsequently followed by a rising trend. In sum, the 'Net' effect of US banks declines from 2012 after a consistent rising while the 'Net' effect of European banks shows a reverse patten. In 
other words, being analogous to the long term directional connectedness, in the short term, the shocks arising from European banks tend to be dominantly transmitted to others especially after 2012, which coincides with the burst of European sovereign debt crisis during 2012-2013.

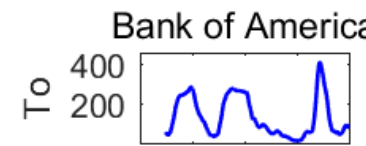

0810121416

Deutsche Bank



0810121416

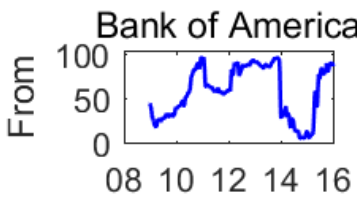

0810121416

Deutsche Bank

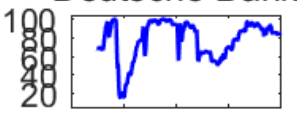

0810121416

Bank of America

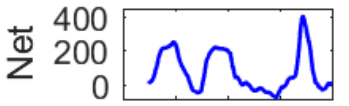

0810121416

Deutsche Bank

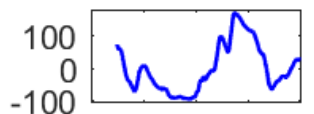

0810121416

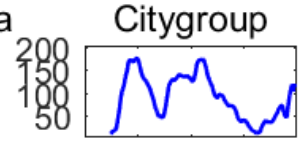

0810121416
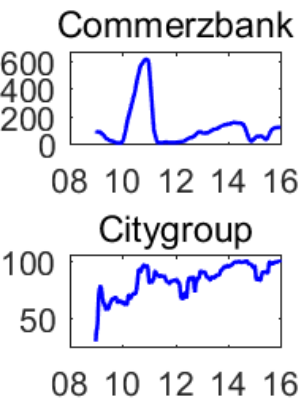

Commerzbank

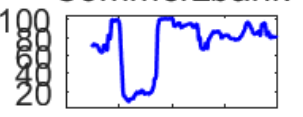

0810121416

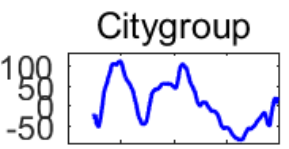

0810121416

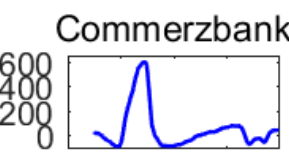

0810121416

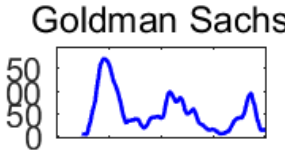

0810121416

Barclays Bank

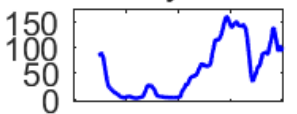

0810121416

Goldman Sachs
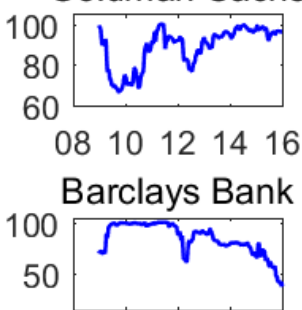

0810121416

Goldman Sachs

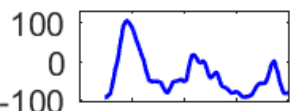

0810121416

Barclays Bank

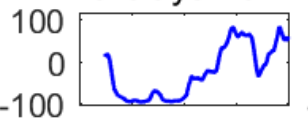

0810121416
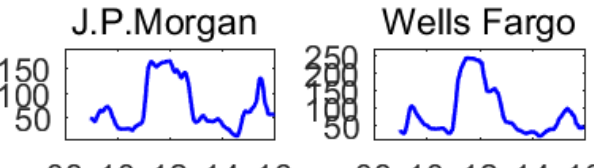

0810121416

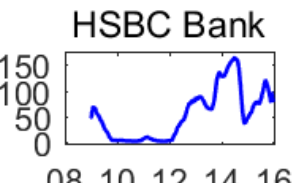

UBS
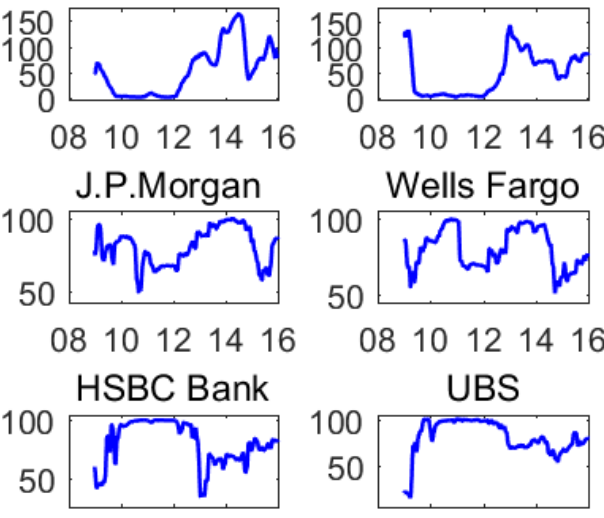

0810121416

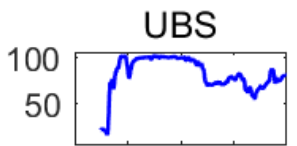

0810121416

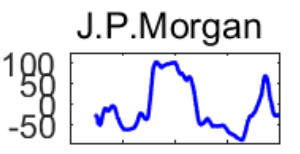

Wells Fargo

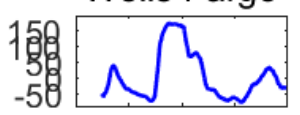

0810121416

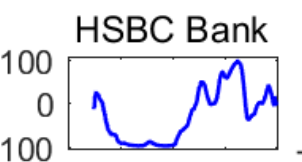

UBS

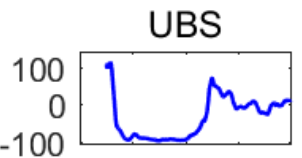

$08 \quad 1012 \quad 14 \quad 16 \quad 0810121416$

Figure 6: Rolling connectedness: curvature factors

Note: Data period: 2009.01.01 - 2015.12.31 with daily data. The DNS factors and the corresponding dynamic of networks are computed by one-year rolling window estimation (260 observations). The variance decomposition is performed by the forecast horizon with 12 days.

Q DDINetwork_network_dynamic

In the three figures, one can see that Bank of America during the period of 2014-15 creates a very promising the 'Net' effect regardless of default horizons. Obviously, BAC is a overwhelming default shock transmitter and needs to be asked for an additional loss buffer. Due to the 2008 acquisition of Countrywide Finance, a high-flying mortgage company that fueled many of the excesses of the housing boom, BAC took huge losses on distressed Countrywide mortgages. In March, 2014, the bank announced unexpected $\$ 6$ billion in mortgage related legal expenses. Additionally, another more than $\$ 16$ billion 
in penalties to settle claims also reported, which turned out to formally announced in August. After these blows, in April, BAC disclosed an significant accounting error of $\$ 4$ billion capital loss undetected for several years. The capital error weighed heavily on the bank shares, which felled by more than $6 \%$ on that trading day, wiping out $\$ 10$ billion in market value, far more than the actual losses. This indicated the collapse of trust from investors, which simultaneously triggered large shocks to other financial institutions.

\subsubsection{Graphical representation}

The network dynamics may be displayed graphically, where the node size and node color are designed to capture the 'To' effect. Meanwhile, directional edge thickness indicates the strength of pairwise directional connectedness, while edge color does not vary with edge weight. Consider 3 snapshots for 2008, 2011 and 2012 in Figure 7.

In 2008, the node size of US banks is apparently larger than that of EU banks, indicating a credit spillover from the US. Besides, the thickness of edge weights implies that the spillover effects are not only closely intertwined among US banks but also transmitted to EU banks (e.g. from GS to DB or CBG, from BAC to $\mathrm{CBG}$ ). This evidence did not yet fade away at the end of 2011 where BAC, JPM, and C are still sizable. However, the node sizes of European banks at the end of 2011 tend to enlarge compared with that in 2008, owning to the continuous negative impact from Greece, Ireland, and Portugal debt crisis. As the European sovereign debt crisis was in its peak at the end of 2012, the European banks turns out to be enormously large, especially for the banks with big market capitalization, such as DB, CBG, and BCS. Further, the edge thickness indicates that the default risk shocks are mutually conducted not only among European banks, but also substantially outflowed from EU banks to US Banks.

\subsection{The network between US and European banks}

In order to have a clear picture on the cross-region spillover effects, we look at two groups, the US v.s. the EU banks, and analyse the dynamics of their default risk transmission.

Figure 8 reveals that the transmission of overall default risk shocks in the long term is 


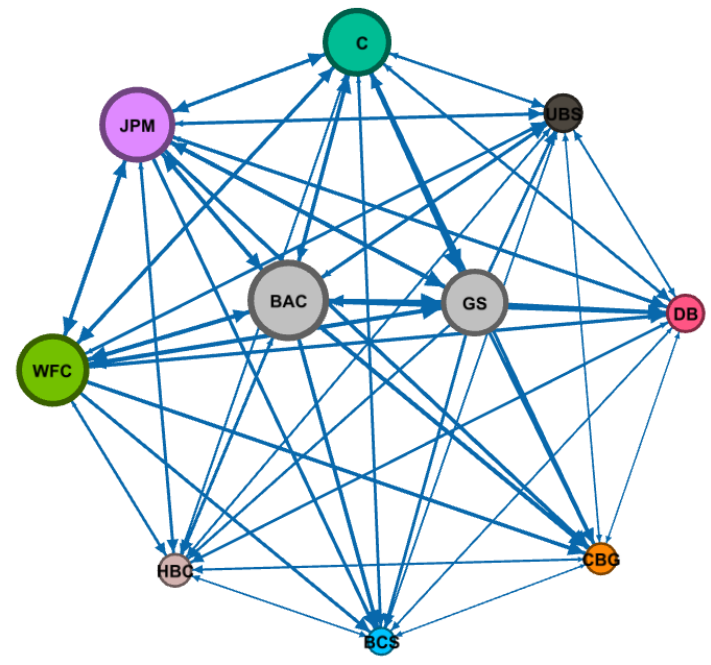

Panel A 2008.12.30

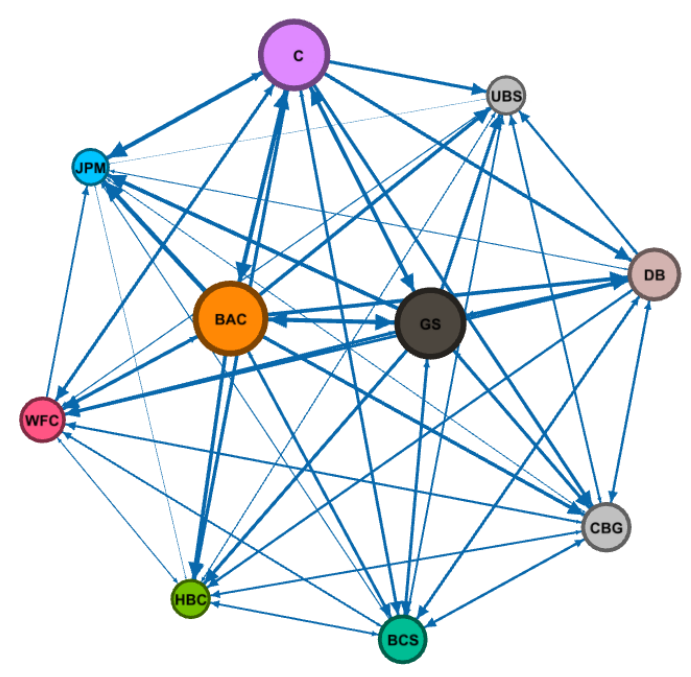

Panel B 2011.12.30

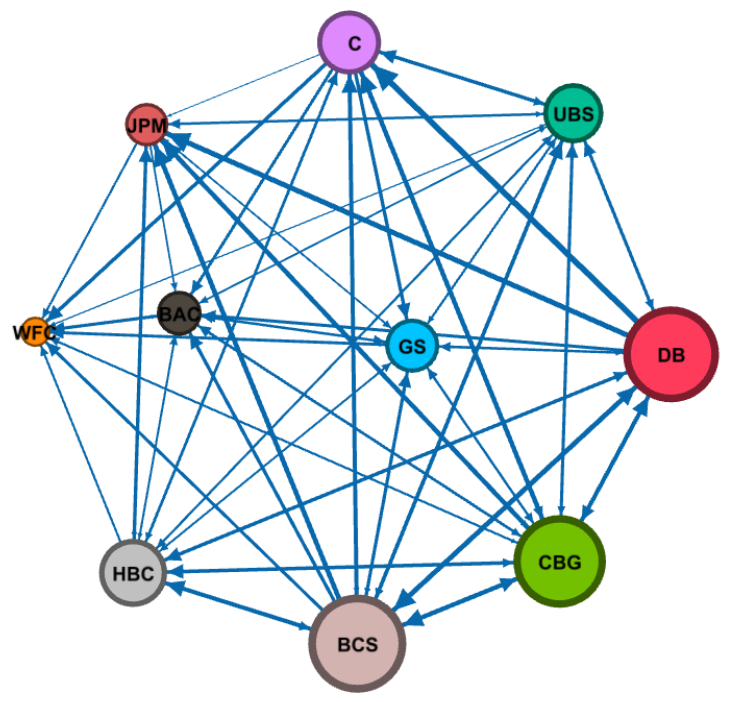

Panel C 2012.12.30

Figure 7: Level pairwise directional connectedness network

Notes: Node size and node color indicate $C_{\bullet \leftarrow i}$ of the bank's level factor. Edge thickness indicates the pairwise directional connectedness. Edge color does not vary with edge weight. 


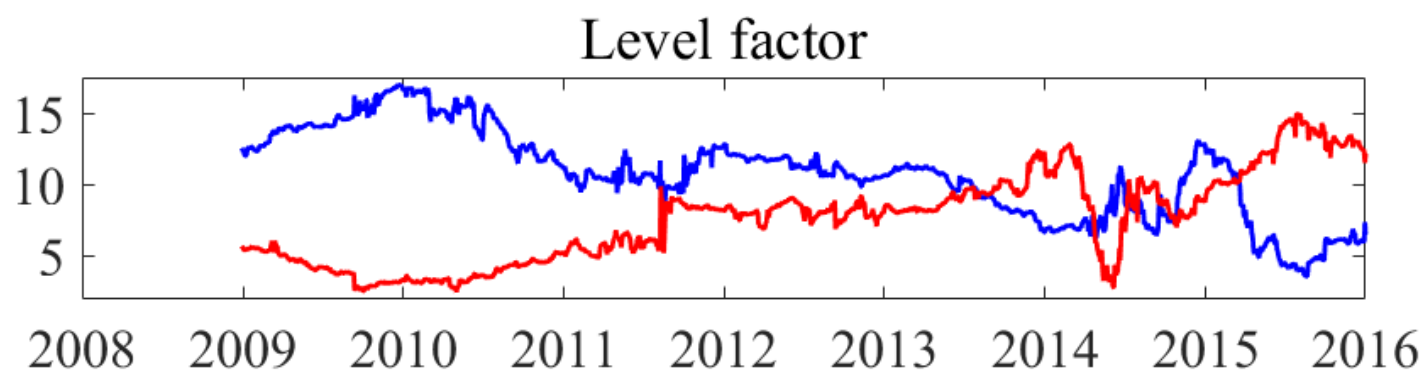

Slope factor
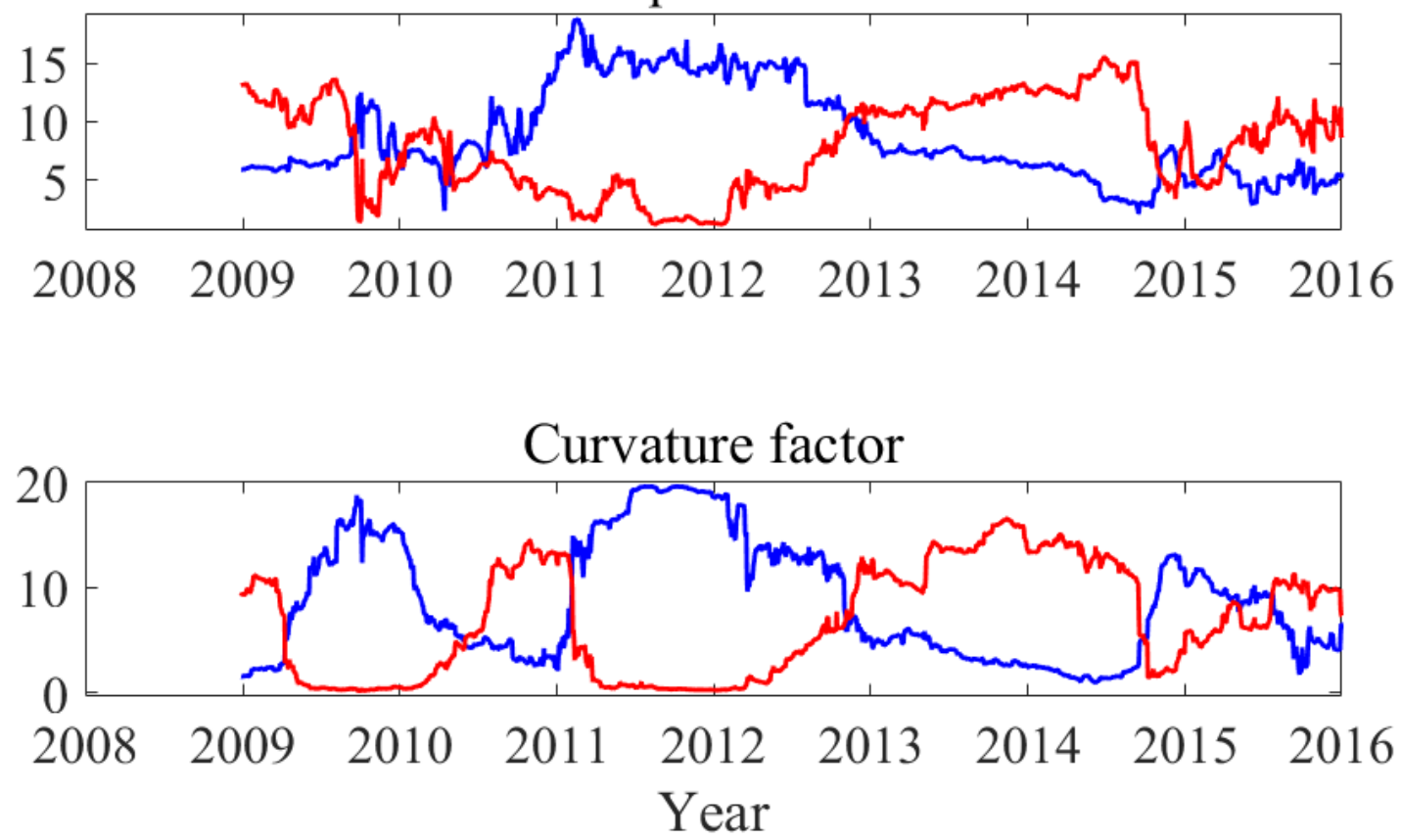

Figure 8: Dynamics of connectedness across US and Europe. The blue line presents the measures from US banks to European banks; the red line presents the measures from European banlss to US banls.

Q DDINetwork_network_US_EU 
getting increased from European banks to US banks since 2010, while that of the short term has a crossing point in 2013 but fall down around 2014, seemingly followed by a new cycle of rising up periods, which is consistent with Figure 3 and Figure 5 . The default shocks still originate from Europe even 5-6 years after the burst of the European sovereign debt crisis.

\subsection{The drivers of default connectedness}

Having the dynamics of default connectedness in a system, we dive deeper to investigate the determinants of this dynamics. In order to understand the evolution of systemic default risk in banking industry and control it further, the policy makers may rely on the model-implied indicators for monitoring the frailty of default in a system. In our analysis, the total connectedness can be viewed as an overall measure of system default risk, in which a high value implies widespread default risk. Hence, in this part, we take the total connectedness derived from level factor, slope factor, and curvature factor in section 5.2.1 as a measure of long term, short term, and middle term systemic default risk respectively, and opt for a vector of state variables to analyse what drive the systematic default risk. We estimate the following regression on the basis of daily data for the determinants of the connectedness of credit curves:

$$
C_{\omega, t}=\alpha_{\omega}+\beta_{\omega}^{\top} M_{t-1}+\varepsilon_{\omega, t}, \quad \varepsilon_{\omega, t} \sim \mathrm{N}\left(0, \sigma^{2}\right)
$$

where $C_{\omega, t}$ denotes total connectedness of level factor, slope factor, and curvature factor at time $t$ respectively, $\omega=\{l, s, c\} . M_{t-1}$ denotes state variables at time $t-1$.

Adrian and Brunnermeier (2016) propose to use the following macro published variables, e.g. (1) The change in the three-month yield; (2) The change in the slope of the yield curve, measured by the spread between the composite long-term bond yield and the three-month bill rate; (3) A short-term TED spread, defined as the difference between the three-month LIBOR rate and the three-month secondary market Treasury bill rate. This spread measures short-term funding liquidity risk. (4) The change in the credit spread between Moody's Baa-rated bonds and the ten-year Treasury rate; (5) The daily market return computed from the S\&P500; (6) The daily real estate sector return in 
excess of the market financial sector return; (7) VIX; In addition we employ common principal components $(\mathrm{CPC})$ the average variance explained by the first principle component through the common principle component approach (CPCA), see (Flury, 1984 ; Fengler et al., 2003, Chen and Härdle, 2015). The CPC factor here is used to capture a common factor which may not be directly observed.

Estimating PCs simultaneously in different groups (banks) can result in a joint dimension reduction transformation, as well as yielding a joint eigenstructure across groups (banks). The basic assumption of CPCA is that the space spanned by the eigenvectors is identical across several groups (banks), whereas variances associated with the components are allowed to vary. The CPCA essentially tests whether the principal components for different banks are the same across different maturities. More formally, for the covariance matrix across $K$ different maturities of bank $i, \Psi_{i}$, the hypothesis of CPCA is:

$$
H_{C P C}: \Psi_{i}=\Gamma \Lambda_{i} \Gamma^{\top}, i=1, \ldots, N
$$

where $\Psi_{i}$ is $K \times K$ positive definite covariance matrix; $\Gamma=\left(\gamma_{1}, \ldots, \gamma_{K}\right)$ is an $K \times K$ orthogonal eigenvector matrix, which is identical for $N$ banks; $\Lambda_{i}=\operatorname{diag}\left(\lambda_{i 1}, \ldots, \lambda_{i K}\right)$ is an diagonal eigenvalues matrix of bank $i$. The estimation details are refered to Appendix 7.2. Through averaging the variance explained by first principal component of each bank, we estimate the CPC variance explained variable using a fix rolling window of 260 observations, in line with the similar procedure in section 5.2.1.

Table 6 provides summary statistics of the total connectedness and state variables. In line with the previous results in section 5.1, the mean value of total connectedness of level factor is larger than that of slope factor, followed by that of curvature factor. The negative skewness values as well as kurtosis values nearly 3 indicate that total connectedness measures seem following right-skewed asymmetric normal distribution. As for CPC first factor variance explained variable, the range is roughly $13 \%-92 \%$, reasonable with large deviation of $15 \%$.

After standardizing all the variables in Table 7, we obtain the estimated parameters through (25) in Table 8. In column 'NW' and column 'HH', the values in parentheses under the corresponding estimated parameters, present $t$-statistics based on Newey-West 
Table 7: Summary of variables

\begin{tabular}{lrrrrrr}
\hline \hline & Mean & S.t.d. & Skew & Kurt & Min & Max \\
\hline Total connectedness: Level & 86.99 & 2.63 & -1.26 & 3.47 & 79.61 & 90.26 \\
Total connectedness: Slope & 84.07 & 4.60 & -1.15 & 3.49 & 69.52 & 90.44 \\
Total connectedness: Curvature & 78.37 & 6.09 & -0.88 & 3.66 & 55.39 & 89.18 \\
Three month yield change & 0.01 & 1.18 & 0.22 & 7.84 & -7.00 & 6.00 \\
Term spread change & 0.00 & 5.76 & -0.15 & 6.24 & -48.00 & 25.00 \\
TED spread & 29.35 & 19.21 & 2.85 & 11.67 & 8.76 & 133.50 \\
Credit spread change & -0.15 & 2.78 & 0.34 & 11.46 & -14.00 & 28.00 \\
Market return & 0.05 & 1.11 & -0.27 & 7.69 & -6.90 & 6.84 \\
Real estate excess return & 0.00 & 0.93 & 0.01 & 10.92 & -6.00 & 6.98 \\
VIX & 20.17 & 8.04 & 1.58 & 5.27 & 10.32 & 56.65 \\
CPC first factor variance explained & 50.77 & 15.06 & 0.26 & 2.69 & 13.35 & 92.64 \\
\hline \hline
\end{tabular}

Note: Data period: 2009.01.01 - 2015.12.31 with daily data. The change, return data, and CPC factor variance explained are in percentage. We list the standard deviation (S.t.d.), skewness (Skew), kurtosis (Kurt) and so on.

Table 8: Determinants of Total connectedness

\begin{tabular}{ccccccc}
\hline \hline & \multicolumn{2}{c}{ Level } & \multicolumn{2}{c}{ Slope } & \multicolumn{2}{c}{ Curvature } \\
\cline { 2 - 7 } & NW & HH & NW & HH & NW & HH \\
\hline Three month yield & 0.010 & 0.010 & -0.007 & -0.007 & -0.003 & -0.003 \\
change & $(0.682)$ & $(0.590)$ & $(-0.490)$ & $(-0.385)$ & $(-0.197)$ & $(-0.184)$ \\
Term spread & -0.016 & -0.016 & -0.009 & -0.009 & 0.001 & 0.001 \\
change & $(-0.888)$ & $(-0.746)$ & $(-0.453)$ & $(-0.406)$ & $(0.025)$ & $(0.026)$ \\
TED spread & $0.125^{* * *}$ & $0.125^{* *}$ & $0.153^{* * *}$ & $0.153^{* *}$ & $-0.363^{* * *}$ & $-0.363^{* * *}$ \\
& $(2.483)$ & $(1.906)$ & $(3.286)$ & $(2.289)$ & $(-4.473)$ & $(-5.811)$ \\
Credit spread & $0.056^{* * *}$ & $0.056^{* *}$ & $0.044^{* *}$ & $0.044^{*}$ & $0.042^{*}$ & $0.042^{*}$ \\
change & $(3.035)$ & $(2.107)$ & $(2.108)$ & $(1.631)$ & $(1.543)$ & $(1.644)$ \\
Market return & $-0.046^{* * *}$ & $-0.046^{* *}$ & -0.018 & -0.018 & -0.022 & -0.022 \\
& $(-2.550)$ & $(-2.082)$ & $(-0.953)$ & $(-0.805)$ & $(-0.954)$ & $(-1.044)$ \\
Real estate excess & -0.005 & -0.005 & -0.021 & -0.021 & -0.023 & -0.023 \\
return & $(-0.260)$ & $(-0.213)$ & $(-1.061)$ & $(-0.950)$ & $(-1.078)$ & $(-1.110)$ \\
VIX & $0.298^{* * *}$ & $0.298^{* * *}$ & -0.010 & -0.010 & $-0.120^{*}$ & $-0.120^{* *}$ \\
& $(4.886)$ & $(4.545)$ & $(-0.170)$ & $(-0.151)$ & $(-1.428)$ & $(-1.924)$ \\
CPC factor & $0.303^{* * *}$ & $0.303^{* * *}$ & $0.434^{* * *}$ & $0.434^{* * *}$ & $0.260^{* * *}$ & $0.260^{* * *}$ \\
variance explained & $(7.996)$ & $(8.543)$ & $(11.793)$ & $(11.994)$ & $(9.119)$ & $(7.677)$ \\
Adjusted $R^{2}(\%)$ & 23.04 & 23.04 & 19.91 & 19.91 & 29.79 & 29.79 \\
\hline \hline
\end{tabular}

Note: $* * *, * *, *$ denotes the significance at the level of $1 \%, 5 \%$ and $10 \%$ respectively. 'NW' presents that the $t$-statistics displayed in parentheses are calculated by Newey-West standard errors allowing for up to 5 periods of autocorrelation. 'HH' represent the $t$-statistics displayed in parentheses are calculated by Hansen and Hodrick standard errors with 5 periods of lag.

standard errors (Newey et al., 1987), and Hansen-Hodrick standard errors (Hansen and Hodrick, 1980) respectively, both with 5 periods of lag. Besides, the last line reports the adjusted $R^{2}$ value of the model. 
In Table 8, higher VIX, higher TED spread, higher credit spread, and lower market return result in high long term default risk. The short-run connectedness is driven by the TED spread and credit spread, while the medium-run one is sensitive to the TED spread and VIX. The CPC factor used to capture the latent common factor is significant across the LT, MT and ST connectedness, implying the existing latent determinants need to be discovered more. Overall, the average significance of the conditioning variables reported in Table 8 show that the state variables do indeed proxy for the time variation in the total connectedness and particularly in the long-term one.

\subsection{Out-of-sample forecasts}

To validate the necessity to incorporate the network information while estimating the CDS curve, we compare the performance between the DNS and the network-perspective DNS model in forecasting CDS spreads. The forecast horizons are selected as 1 day, 5 days, and 10 days. Following the framework in section 2.3 , we report the difference of root mean squared errors (RMSE)between them. When taking the European crisis period, from 2011 to 2013, as the out-of-sample forecast period, Figure 9 presents the results of GS and HSBC bank as examples. Each point denotes the difference between the RMSE of network DNS model and that of DNS model at each maturity period, and the resulting negative value in the difference indicates the superiority of the model with network perspective. One can observe the negative values in the difference of RMSE and they are homogenously distributed in the majority of maturities, especially as forecast horizons increase. It reveals that RMSE of forecasting CDS spreads in network DNS model is smaller than that of DNS model, the network DNS model performs even better as the forecast horizon increase.

Through overall summarizing the performance of European banks and US banks, we present the average value of RMSE difference under these two models in Table 9. It reveals a similar pattern to what has been discovered in Figure 9. More interestingly, the more frequent negative values shown in the EU group implies that the network information advantage in forecasting CDS curve seems to be supported more in the EU area. Predicting the CDS curve in EU banks one has to opt for a network-perspective 

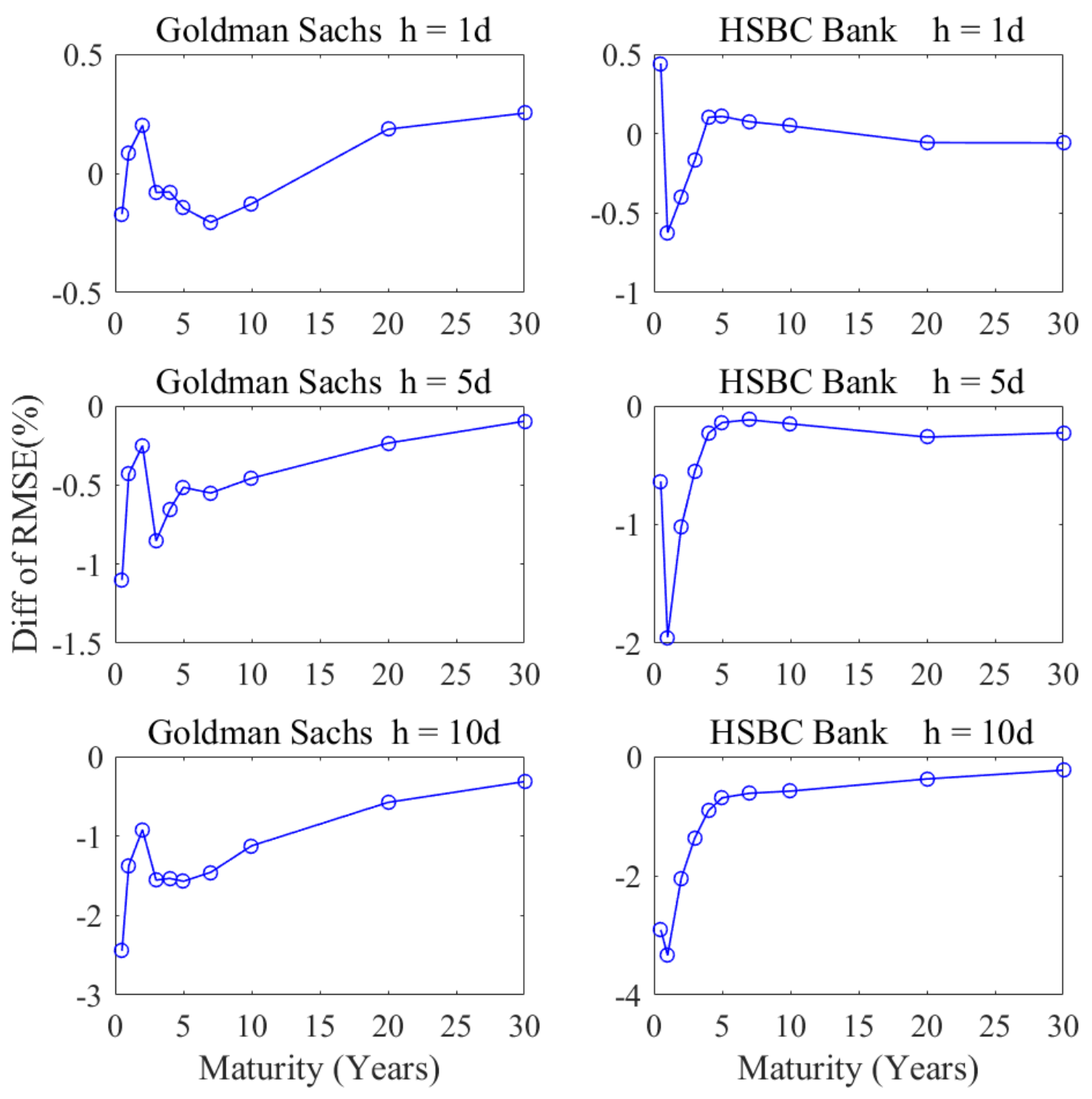

Figure 9: Difference of RMSE of CDS spreads forecast between network DNS model and DNS model, for horizon $h=\{1$ day, 5day, 10day $\}$. The left panel lists the values of Goldman Sachs, the right panel for HSBC bank. The points correspond to different maturities. The forecast period is 2011.01.01 - 2013.12.31. 
model. The prediction can be used to decide the timing of entering CDS contract to lock up the hedge cost in term of default from the buyer side. For the seller side, they avoid underestimating CDS price after incorporating default spillover through their network.

Table 10 reports the Diebold-Mariano test statistics (Diebold and Mariano, 1995) to compare the network DNS model versus DNS model forecasts. In the Diebold-Mariano (DM) test, we conduct a pairwise test on the equality of the mean squared forecast errors by analyzing the difference between the squared forecast errors of the network DNS model and the DNS model, $e_{t, n e t}^{2}-e_{t}^{2}=\mu+\varepsilon_{t}$. The null hypothesis of equal performance is that $H_{0}: \mu=0$. We focus on the $t$-statistics of parameter $\mu$, denoted as DM $t$-stat, which supports the network DNS model if it is significantly negative (significance level marked by asterisks). Regardless the forecast horizons, we find the negative DM $t$-stat are prevalent for the maturities less than $10 \mathrm{Y}$ lying on the CDS curves. In other words, the network DNS model is superior than the DNS model in out-of-sample forecast, especially for the EU CDS curves.

Table 9: US and EU: out-of-sample forecast

\begin{tabular}{|c|c|c|c|c|c|c|c|c|c|c|c|}
\hline & $h$ & $6 \mathrm{M}$ & $1 \mathrm{Y}$ & $2 \mathrm{Y}$ & $3 Y$ & $4 \mathrm{Y}$ & $5 \mathrm{Y}$ & $7 \mathrm{Y}$ & $10 \mathrm{Y}$ & $20 \mathrm{Y}$ & 30 \\
\hline \multirow{3}{*}{ US } & $1 \mathrm{~d}$ & .156 & .029 & 0.094 & -0.031 & -0.102 & -0.076 & -0.029 & -0.026 & 0.158 & 0.198 \\
\hline & $5 d$ & -0.132 & -0.235 & -0.116 & -0.356 & -0.318 & -0.108 & 0.140 & -0.037 & -0.031 & 0.092 \\
\hline & $10 \mathrm{~d}$ & -0.609 & -0.637 & -0.209 & -0.480 & -0.597 & -0.566 & -0.161 & -0.290 & -0.121 & 0.111 \\
\hline \multirow{3}{*}{$\mathrm{EU}$} & $1 d$ & 0.264 & -0.162 & -0.110 & -0.027 & 0.091 & 0.022 & -0.018 & -0.041 & 0.048 & 0.081 \\
\hline & $5 \mathrm{~d}$ & -0.486 & -0.973 & -0.516 & -0.318 & -0.058 & -0.098 & -0.237 & -0.354 & -0.174 & -0.011 \\
\hline & $10 \mathrm{~d}$ & -1.580 & -1.388 & -0.685 & -0.446 & -0.388 & -0.524 & -0.700 & -0.804 & -0.309 & -0.014 \\
\hline
\end{tabular}

Note: RMSE difference of CDS spreads forecast between network DNS model and DNS model. The values of US and EU banks are averaged in total. The forecast period is 2011.01.01 - 2013.12.31. 
Table 10: Forecast comparison between network DNS model and DNS model: DM test

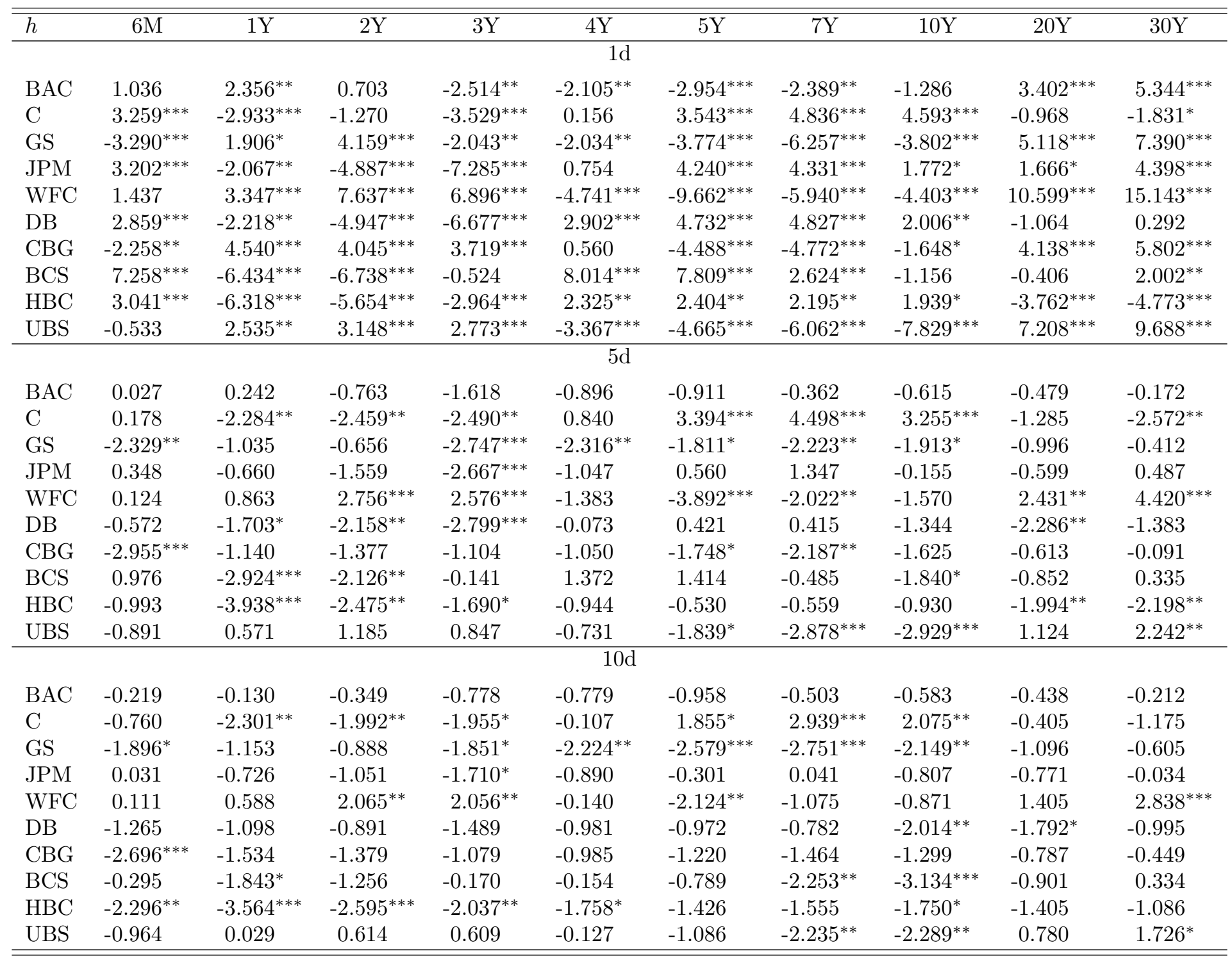

Note: This table gives the t-statistics of Diebold-Mariano test, that is $H_{0}: \mu=0$ in the regression $e_{t, n e t}^{2}-e_{t}^{2}=\mu+\varepsilon_{t}$ where $e_{t, n e t}$ and $e_{t}$ denote the forecast error of network DNS model and DNS model respectively. The test is modified with robust Newey-West variances for heteroscedasticity and autocorrelation with the lags equal to the forecast horizon. $*$ denotes a significance level of $10 \%, * *$ denotes a significance level of $5 \%, * * *$ denotes a significance level of 1\%. The forecast period is 2011.01.01 - 2013.12.31. 


\section{Conclusions}

Systemic risk, the risk of disruption to financial services, can be teased out directly through an investigation tagging to CDS curves, in comparison with the conventional market-based approach by using stock returns as alternatives such as the CoVaR measure. This study shows the information content of a CDS curve for its term structure implication corresponding to particular credit horizons. The changing shape of credit curve implies the credit deterioration over different time frames (ST, MT or LT), which can be used to manage the credit exposures with different maturities.

The existant literature has paid insufficient attention on the shape of CDS curve, the dynamics of CDS curve and the comovement or interplay between curves. We contribute to the existing literature by (1) using the DNS model to extract the ST, the MT and the LT default factor from a CDS curve; (2) quantifying the comovement of CDS curves through a total connectedness measure to reflect the firms being downgraded simultaneously; (3) measuring the default spillover in the ST, MT and LT perspective, respectively; (4) conducting out-of-sample prediction for CDS curves based on the network-based DNS model.

The evidence from G-SIBs banks shows that the CDS curves comove tightly with higher connectedness, especially in the long-run. The US banks contribute more to the long-run default spillover before 2012, whereas the European banks are major default transmitters during and after the European debt crisis either in the long-run or short-run. The timevarying default connectedness and spillover can be viewed as an indicator for monitoring systemic default risk, especially for identifying the trouble makers triggering a clustered default in a system. We find that the TED spread, credit spread and VIX are main determinants of default connectedness. The outperformance of the network DNS model indicates that the prediction on CDS curve requires network information.

\section{References}

Adrian, T. and Brunnermeier, M. K. (2016). CoVaR, American Economic Review 106(7): 1705-1741. 
Blanco, R., Brennan, S. and Marsh, I. W. (2005). An empirical analysis of the dynamic relation between investment-grade bonds and credit default swaps, The Journal of Finance 60(5): 2255-2281.

Chen, C. Y.-H. and Härdle, W. K. (2015). Common factors in credit defaults swap markets, Computational Statistics 30(3): 845-863.

Diebold, F. X. and Li, C. (2006). Forecasting the term structure of government bond yields, Journal of econometrics 130(2): 337-364.

Diebold, F. X. and Mariano, R. S. (1995). Comparing predictive accuracy, Journal of Business and Economic Statistics 20(1): 253-263.

Diebold, F. X., Rudebusch, G. D. and Aruoba, S. B. (2006). The macroeconomy and the yield curve: a dynamic latent factor approach, Journal of Econometrics 131(1): 309338.

Diebold, F. X. and Yllmaz, K. (2014). On the network topology of variance decompositions: Measuring the connectedness of financial firms, Journal of Econometrics 182(1): 119-134.

Duan, J.-C. and Miao, W. (2015). Default Correlations and Large-Portfolio Credit Analysis, Journal of Business $\&$ Economic Statistics (just-accepted): 1-36.

Duffie, D., Eckner, A., Horel, G. and Saita, L. (2009). Frailty correlated default, The Journal of Finance 64(5): 2089-2123.

Ericsson, J., Jacobs, K., Oviedo, R. et al. (2009). The determinants of credit default swap premia, Journal of Financial and Quantitative Analysis 44(1): 109-132.

Fengler, M. R., Härdle, W. K. and Villa, C. (2003). The dynamics of implied volatilities: A common principal components approach, Review of Derivatives Research 6(3): 179202.

Flury, B. N. (1984). Common principal components in $k$ groups, Journal of the American Statistical Association 79(388): 892-898. 
Flury, B. N. and Gautschi, W. (1986). An algorithm for simultaneous orthogonal transformation of several positive definite symmetric matrices to nearly diagonal form, Journal on Scientific and Statistical Computing 7(1): 169-184.

Han, B. and Zhou, Y. (2015). Understanding the term structure of credit default swap spreads, Journal of Empirical Finance 31: 18-35.

Hansen, L. P. and Hodrick, R. J. (1980). Forward exchange rates as optimal predictors of future spot rates: An econometric analysis, The Journal of Political Economy 10: 829853.

Härdle, W. and Simar, L. (2015). Applied multivariate statistical analysis, Fourth edition, Springer.

Koop, G., Pesaran, M. H. and Potter, S. M. (1996). Impulse response analysis in nonlinear multivariate models, Journal of econometrics 74(1): 119-147.

Krishnan, C., Ritchken, P. H. and Thomson, J. B. (2010). Predicting credit spreads, Journal of Financial Intermediation 19(4): 529-563.

Longstaff, F. A., Mithal, S. and Neis, E. (2005). Corporate yield spreads: Default risk or liquidity? New evidence from the credit default swap market, The Journal of Finance 60(5): 2213-2253.

Nelson, C. R. and Siegel, A. F. (1987). Parsimonious modeling of yield curves, Journal of business 10: 473-489.

Newey, W. K., West, K. D. et al. (1987). A Simple, Positive Semi-definite, Heteroskedasticity and Autocorrelation Consistent Covariance Matrix, Econometrica 55(3): 703-08.

Pan, J. and Singleton, K. J. (2008). Default and recovery implicit in the term structure of sovereign CDS spreads, The Journal of Finance 63(5): 2345-2384.

Shaw, F., Murphy, F. and O'Brien, F. (2014). The forecasting efficiency of the dynamic Nelson Siegel model on credit default swaps, Research in International Business and Finance 30: 348-368. 


\section{Appendix}

\subsection{CDS spreads}

\subsection{Common principal component analysis (CPCA)}

Here we introduce the maximum likelihood estimation procedures of CPC under the hypothesis in $(26)$. The theoretical proof and the asymptotic properties of the estimates are referred to Flury (1984) and Flury and Gautschi (1986).

Let $S_{i}$ be the (unbiased) sample covariance matrix of an underlying $K$-variate normal distribution $N_{K}\left(\mu, \Psi_{i}\right)$ with sample size $n_{i}$. Then $n_{i} S_{i}$ follows a Wishart distribution with degrees of freedom $n_{i}-1$, Härdle and Simar (2015)

$$
n_{i} S_{i} \sim \mathcal{W}_{K}\left(\Psi, n_{i}-1\right)
$$

Hence for $N$ Wishart matrices $S_{i}$ with sample size $n_{i}$, the likelihood function is

$$
L\left(\Psi_{1}, \ldots, \Psi_{N}\right)=C \prod_{i=1}^{N} \exp \left\{\operatorname{tr}\left(-\frac{1}{2}\left(n_{i}-1\right) \Psi_{i}^{-1} S_{i}\right)\right\}\left|\Psi_{i}\right|^{-\frac{1}{2}\left(n_{i}-1\right)}
$$

where $C$ is a constant not depending on the parameters $\Psi_{i}$. Maximizing the likelihood is equivalent to minimizing the function

$$
g\left(\Psi_{1}, \ldots, \Psi_{N}\right)=\sum_{i=1}^{N}\left(n_{i}-1\right)\left\{\log \left|\Psi_{i}\right|+\operatorname{tr}\left(\Psi_{i}^{-1} S_{i}\right)\right\}
$$

Assuming that $H_{C P C}$ in Equation (26) holds, replacing $\Psi_{i}$ by $\Gamma \Lambda_{i} \Gamma^{\top}$, yields,

$$
g\left(\Gamma, \Lambda_{1}, \ldots, \Lambda_{N}\right)=\sum_{i=1}^{N}\left(n_{i}-1\right) \sum_{j=1}^{K}\left(\log \lambda_{i j}+\frac{\gamma_{j}^{\top} S_{i} \gamma_{j}}{\lambda_{i j}}\right)
$$

We impose the orthogonal constraints in $\Gamma$ by using the Lagrange multipliers $\mu_{j}$ for the $K$ constraints $\gamma_{j}^{\top} \gamma_{j}=1$, and using the multipliers $\mu_{h j}$ for the remaining $K(K-1) / 2$ 

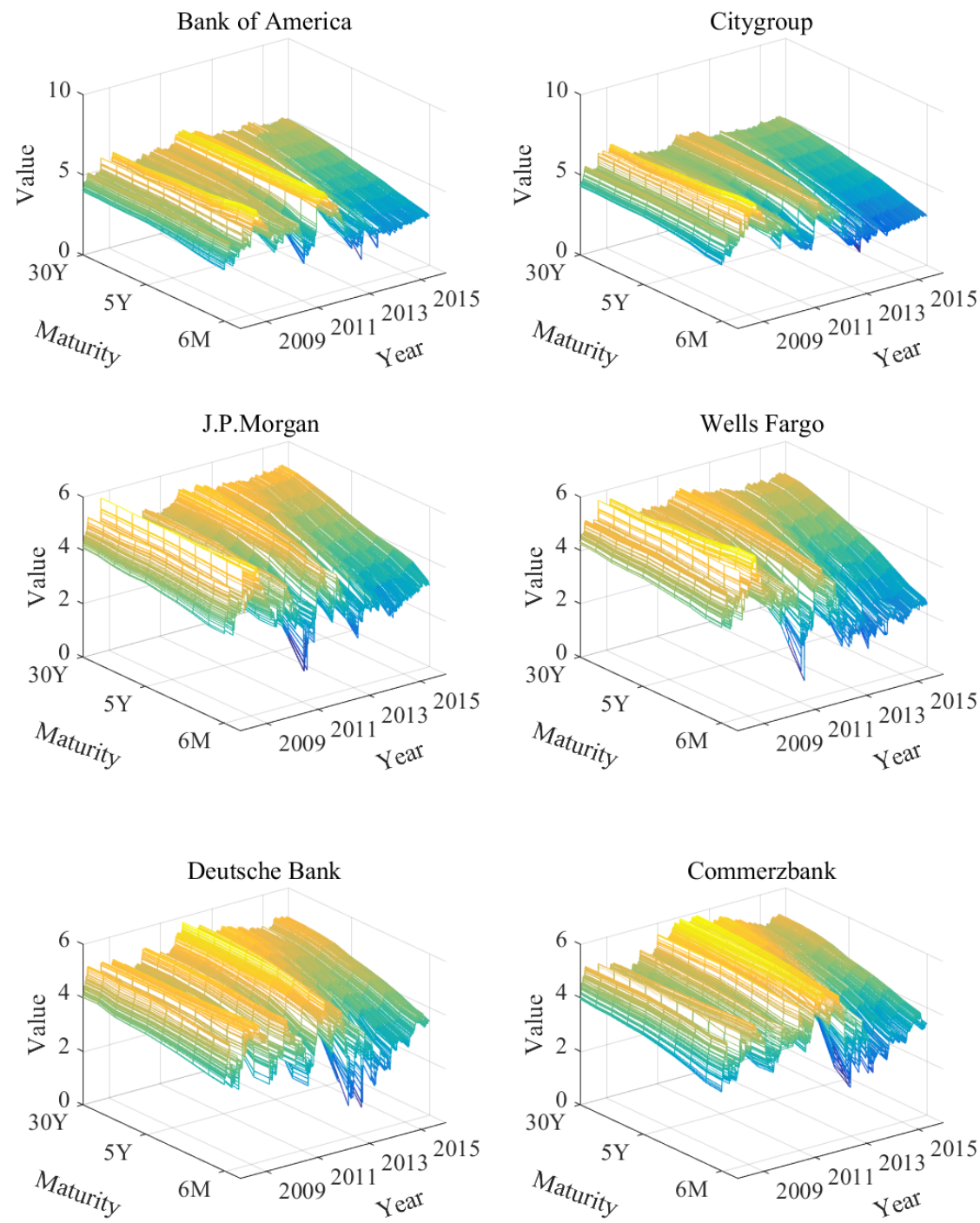

Barclays Bank

UBS
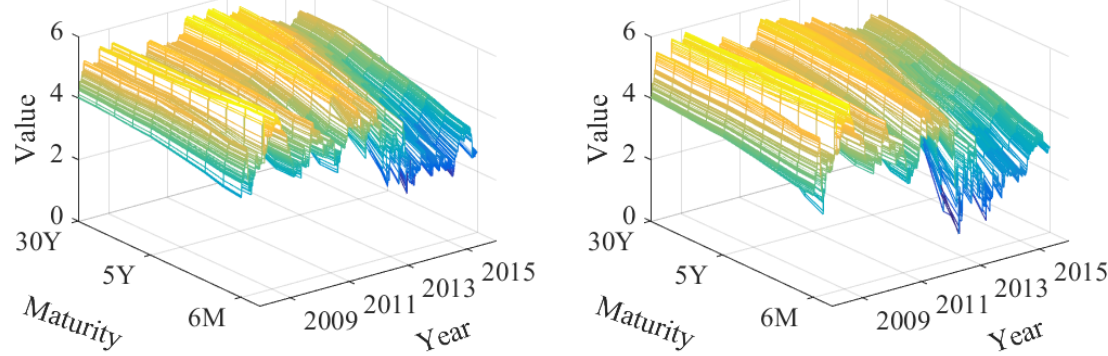

Figure 10: CDS spreads data 
constraints $\gamma_{h}^{\top} \gamma_{j}=0$ for $(h \neq j)$. Hence the Lagrange function is

$$
g^{*}\left(\Gamma, \Lambda_{1}, \ldots, \Lambda_{N}\right)=g(\cdot)-\sum_{j=1}^{K} \mu_{j}\left(\gamma_{j}^{\top} \gamma_{j}-1\right)-2 \sum_{h<j}^{K} \mu_{h j} \gamma_{h}^{\top} \gamma_{j}
$$

Taking partial derivatives with respect to all $\lambda_{i m}$ and $\gamma_{m}$, the solution of the CPC model is given by the generalized system of characteristic equations, Flury (1984)

$$
\gamma_{m}^{\top}\left\{\sum_{i=1}^{N}\left(n_{i}-1\right) \frac{\lambda_{i m}-\lambda_{i j}}{\lambda_{i m} \lambda_{i j}} S_{i}\right\} \gamma_{j}=0, \quad m, j=1, \ldots, K, \quad m \neq j .
$$

This is solved using

$$
\lambda_{i m}=\gamma_{m}^{\top} S \gamma_{m}, \quad i=1, \ldots, N, \quad m=1, \ldots, K
$$

under the constraints

$$
\gamma_{m}^{\top} \gamma_{j}= \begin{cases}0 & m \neq j \\ 1 & m=j\end{cases}
$$

Flury (1984) proves existence and uniqueness of the maximum of the likelihood function, and Flury and Gautschi (1986) provide a numerical algorithm. 


\section{SFB 649 Discussion Paper Series 2016}

For a complete list of Discussion Papers published by the SFB 649, please visit http://sfb649. wiwi.hu-berlin.de.

001 "Downside risk and stock returns: An empirical analysis of the long-run and short-run dynamics from the G-7 Countries" by Cathy Yi-Hsuan Chen, Thomas C. Chiang and Wolfgang Karl Härdle, January 2016.

002 "Uncertainty and Employment Dynamics in the Euro Area and the US" by Aleksei Netsunajev and Katharina Glass, January 2016.

003 "College Admissions with Entrance Exams: Centralized versus Decentralized" by Isa E. Hafalir, Rustamdjan Hakimov, Dorothea Kübler and Morimitsu Kurino, January 2016.

004 "Leveraged ETF options implied volatility paradox: a statistical study" by Wolfgang Karl Härdle, Sergey Nasekin and Zhiwu Hong, February 2016.

005 "The German Labor Market Miracle, 2003 -2015: An Assessment" by Michael C. Burda, February 2016.

006 "What Derives the Bond Portfolio Value-at-Risk: Information Roles of Macroeconomic and Financial Stress Factors" by Anthony H. Tu and Cathy Yi-Hsuan Chen, February 2016.

007 "Budget-neutral fiscal rules targeting inflation differentials" by Maren Brede, February 2016.

008 "Measuring the benefit from reducing income inequality in terms of GDP" by Simon Voigts, February 2016.

009 "Solving DSGE Portfolio Choice Models with Asymmetric Countries" by Grzegorz R. Dlugoszek, February 2016.

010 "No Role for the Hartz Reforms? Demand and Supply Factors in the German Labor Market, 1993-2014" by Michael C. Burda and Stefanie Seele, February 2016.

011 "Cognitive Load Increases Risk Aversion" by Holger Gerhardt, Guido P. Biele, Hauke R. Heekeren, and Harald Uhlig, March 2016.

012 "Neighborhood Effects in Wind Farm Performance: An Econometric Approach" by Matthias Ritter, Simone Pieralli and Martin Odening, March 2016.

013 "The importance of time-varying parameters in new Keynesian models with zero lower bound" by Julien Albertini and Hong Lan, March 2016.

014 "Aggregate Employment, Job Polarization and Inequalities: A Transatlantic Perspective" by Julien Albertini and Jean Olivier Hairault, March 2016.

015 "The Anchoring of Inflation Expectations in the Short and in the Long Run" by Dieter Nautz, Aleksei Netsunajev and Till Strohsal, March 2016.

016 "Irrational Exuberance and Herding in Financial Markets" by Christopher Boortz, March 2016.

017 "Calculating Joint Confidence Bands for Impulse Response Functions using Highest Density Regions" by Helmut Lütkepohl, Anna StaszewskaBystrova and Peter Winker, March 2016.

018 "Factorisable Sparse Tail Event Curves with Expectiles" by Wolfgang K. Härdle, Chen Huang and Shih-Kang Chao, March 2016.

019 "International dynamics of inflation expectations" by Aleksei Netšunajev and Lars Winkelmann, May 2016.

020 "Academic Ranking Scales in Economics: Prediction and Imdputation" by Alona Zharova, Andrija Mihoci and Wolfgang Karl Härdle, May 2016.

\section{SFB 649, Spandauer Straße 1, D-10178 Berlin http:/ / sfb649.wiwi.hu-berlin.de}

This research was supported by the Deutsche Forschungsgemeinschaft through the SFB 649 "Economic Risk".

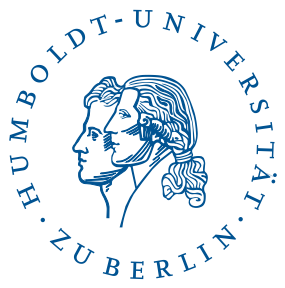




\section{SFB 649 Discussion Paper Series 2016}

For a complete list of Discussion Papers published by the SFB 649, please visit http://sfb649.wiwi.hu-berlin.de.

021 "CRIX or evaluating blockchain based currencies" by Simon Trimborn and Wolfgang Karl Härdle, May 2016.

022 "Towards a national indicator for urban green space provision and environmental inequalities in Germany: Method and findings" by Henry Wüstemann, Dennis Kalisch, June 2016.

023 "A Mortality Model for Multi-populations: A Semi-Parametric Approach" by Lei Fang, Wolfgang K. Härdle and Juhyun Park, June 2016.

024 "Simultaneous Inference for the Partially Linear Model with a Multivariate Unknown Function when the Covariates are Measured with Errors" by Kun Ho Kim, Shih-Kang Chao and Wolfgang K. Härdle, August 2016.

025 "Forecasting Limit Order Book Liquidity Supply-Demand Curves with Functional AutoRegressive Dynamics" by Ying Chen, Wee Song Chua and Wolfgang K. Härdle, August 2016.

026 "VAT multipliers and pass-through dynamics" by Simon Voigts, August 2016.

027 "Can a Bonus Overcome Moral Hazard? An Experiment on Voluntary Payments, Competition, and Reputation in Markets for Expert Services" by Vera Angelova and Tobias Regner, August 2016.

028 "Relative Performance of Liability Rules: Experimental Evidence" by Vera Angelova, Giuseppe Attanasi, Yolande Hiriart, August 2016.

029 "What renders financial advisors less treacherous? On commissions and reciprocity" by Vera Angelova, August 2016.

030 "Do voluntary payments to advisors improve the quality of financial advice? An experimental sender-receiver game" by Vera Angelova and Tobias Regner, August 2016.

031 "A first econometric analysis of the CRIX family" by Shi Chen, Cathy YiHsuan Chen, Wolfgang Karl Härdle, TM Lee and Bobby Ong, August 2016.

032 "Specification Testing in Nonparametric Instrumental Quantile Regression" by Christoph Breunig, August 2016.

033 "Functional Principal Component Analysis for Derivatives of Multivariate Curves" by Maria Grith, Wolfgang K. Härdle, Alois Kneip and Heiko Wagner, August 2016.

034 "Blooming Landscapes in the West? - German reunification and the price of land." by Raphael Schoettler and Nikolaus Wolf, September 2016.

035 "Time-Adaptive Probabilistic Forecasts of Electricity Spot Prices with Application to Risk Management." by Brenda López Cabrera , Franziska Schulz, September 2016.

036 "Protecting Unsophisticated Applicants in School Choice through Information Disclosure" by Christian Basteck and Marco Mantovani, September 2016.

037 "Cognitive Ability and Games of School Choice" by Christian Basteck and Marco Mantovani, Oktober 2016.

038 "The Cross-Section of Crypto-Currencies as Financial Assets: An Overview" by Hermann Elendner, Simon Trimborn, Bobby Ong and Teik Ming Lee, Oktober 2016.

039 "Disinflation and the Phillips Curve: Israel 1986-2015" by Rafi Melnick and Till Strohsal, Oktober 2016.

\section{SFB 649, Spandauer Straße 1, D-10178 Berlin http:/ / sfb649.wiwi.hu-berlin.de}

This research was supported by the Deutsche Forschungsgemeinschaft through the SFB 649 "Economic Risk".

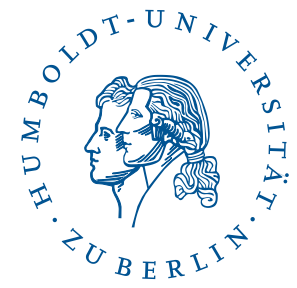




\section{SFB 649 Discussion Paper Series 2016}

For a complete list of Discussion Papers published by the SFB 649, please visit http://sfb649.wiwi.hu-berlin.de.

040 "Principal Component Analysis in an Asymmetric Norm" by Ngoc M. Tran, Petra Burdejová, Maria Osipenko and Wolfgang K. Härdle, October 2016.

041 "Forward Guidance under Disagreement - Evidence from the Fed's Dot Projections" by Gunda-Alexandra Detmers, October 2016.

042 "The Impact of a Negative Labor Demand Shock on Fertility - Evidence from the Fall of the Berlin Wall" by Hannah Liepmann, October 2016.

043 "Implications of Shadow Bank Regulation for Monetary Policy at the Zero Lower Bound" by Falk Mazelis, October 2016.

044 "Dynamic Contracting with Long-Term Consequences: Optimal CEO Compensation and Turnover" by Suvi Vasama, October 2016.

045 "Information Acquisition and Liquidity Dry-Ups" by Philipp Koenig and David Pothier, October 2016.

046 "Credit Rating Score Analysis" by Wolfgang Karl Härdle, Phoon Kok Fai and David Lee Kuo Chuen, November 2016.

047 "Time Varying Quantile Lasso" by Lenka Zbonakova, Wolfgang Karl Härdle, Phoon Kok Fai and Weining Wang, November 2016.

048 "Unraveling of Cooperation in Dynamic Collaboration" by Suvi Vasama, November 2016.

049 "Q3-D3-LSA" by Lukas Borke and Wolfgang K. Härdle, November 2016.

050 "Network Quantile Autoregression" by Xuening Zhu, Weining Wang, Hangsheng Wang and Wolfgang Karl Härdle, November 2016.

051 "Dynamic Topic Modelling for Cryptocurrency Community Forums" by Marco Linton, Ernie Gin Swee Teo, Elisabeth Bommes, Cathy Yi-Hsuan Chen and Wolfgang Karl Härdle, November 2016.

052 "Beta-boosted ensemble for big credit scoring data" by Maciej Zieba and Wolfgang Karl Härdle, November 2016.

053 "Central Bank Reputation, Cheap Talk and Transparency as Substitutes for Commitment: Experimental Evidence" by John Duffy and Frank Heinemann, December 2016.

054 "Labor Market Frictions and Monetary Policy Design" by Anna Almosova, December 2016.

055 "Effect of Particulate Air Pollution on Coronary Heart Disease in China: Evidence from Threshold GAM and Bayesian Hierarchical Model" by Xiaoyu Chen, December 2016.

056 "The Effect of House Price on Stock Market Participation in China: Evidence from the CHFS Micro-Datal" by Xiaoyu Chen and Xiaohao Ji, December 2016.

057 "Factorisable Multi-Task Quantile Regression" by Shih-Kang Chao, Wolfgang K. Härdle and Ming Yuan, December 2016.

058 "Multivariate Factorisable Sparse Asymmetric Least Squares Regression" by Shih-Kang Chao, Wolfgang K. Härdle and Chen Huang, December 2016.

059 "Dynamic credit default swaps curves in a network topology" by Xiu Xu, Cathy Yi-Hsuan Chen and Wolfgang Karl Härdle, December 2016.

\section{SFB 649, Spandauer Straße 1, D-10178 Berlin} http:/ / sfb649.wiwi.hu-berlin.de 